\title{
NEGOTIATIONS ON ARTICLE 6 OF THE PARIS AGREEMENT - ROAD TO MADRID
}

Andrei Marcu and Virender Kumar Duggal

NO. 63

November 2019

\section{ADB SUSTAINABLE DEVELOPMENT WORKING PAPER SERIES}





\section{ADB Sustainable Development Working Paper Series}

\section{Negotiations on Article 6 of the Paris Agreement \\ - Road to Madrid}

Andrei Marcu and Virender Kumar Duggal

No. 63 | November 2019
Andrei Marcu is the Managing Director of the European Roundtable on Climate and Sustainable

Transition based in Brussels, Belgium.

Virender Kumar Duggal is a Principal Climate Change Specialist at the Climate Change and Disaster Risk Management Division under the Sustainable Development and Climate Change Department of the Asian Development Bank. 
(C) 2019 Asian Development Bank

6 ADB Avenue, Mandaluyong City, 1550 Metro Manila, Philippines

Tel +632 8632 4444; Fax +63286362444

www.adb.org

Some rights reserved. Published in 2019.

Publication Stock No. WPS190559-2

DOI: http://dx.doi.org/10.22617/WPS190559-2

The views expressed in this publication are those of the authors and do not necessarily reflect the views and policies of the Asian Development Bank (ADB) or its Board of Governors or the governments they represent.

ADB does not guarantee the accuracy of the data included in this publication and accepts no responsibility for any consequence of their use. The mention of specific companies or products of manufacturers does not imply that they are endorsed or recommended by ADB in preference to others of a similar nature that are not mentioned.

By making any designation of or reference to a particular territory or geographic area, or by using the term "country" in this document, $A D B$ does not intend to make any judgments as to the legal or other status of any territory or area.

This work is available under the Creative Commons Attribution 3.0 IGO license (CC BY 3.0 IGO)

https://creativecommons.org/licenses/by/3.0/igo/. By using the content of this publication, you agree to be bound by the terms of this license. For attribution, translations, adaptations, and permissions, please read the provisions and terms of use at https://www.adb.org/terms-use\#openaccess.

This CC license does not apply to non-ADB copyright materials in this publication. If the material is attributed to another source, please contact the copyright owner or publisher of that source for permission to reproduce it. ADB cannot be held liable for any claims that arise as a result of your use of the material.

Please contact pubsmarketing@adb.org if you have questions or comments with respect to content, or if you wish to obtain copyright permission for your intended use that does not fall within these terms, or for permission to use the ADB logo.

The ADB Sustainable Development Working Paper Series presents data, information, and/or findings from ongoing research and studies to encourage exchange of ideas and elicit comment and feedback about development issues in Asia and the Pacific. Since papers in this series are intended for quick and easy dissemination, the content may or may not be fully edited and may later be modified for final publication.

Corrigenda to ADB publications may be found at http://www.adb.org/publications/corrigenda. 


\section{CONTENTS}

$\begin{array}{ll}\text { I. BACKGROUND } & 1\end{array}$

$\begin{array}{ll}\text { II. ISSUES } & 2\end{array}$

A. Outcomes of the 24th Conference of the Parties 2

B. Key Areas of Divergence $\quad 6$

C. Outcomes of the 50th Meeting of the Subsidiary

Body for Scientific and Technological Advice 8

D. Organizational Matters 9

E. Reflections on Article 6.8

III. WAY FORWARD TO COP 25

$\begin{array}{ll}\text { IV. POTENTIAL OBSTACLES } & 15\end{array}$

$\begin{array}{lll}\text { V. CONCLUSIONS } & 18\end{array}$

APPENDIXES

APPENDIX 1: Draft Conference of the Parties serving as the Meeting of the Parties to the Paris Agreement decision on guidance on cooperative approaches referred to in Article 6, Paragraph 2, of the Paris Agreement

APPENDIX 2: Draft Conference of the Parties serving as the Meeting of the Parties to the Paris Agreement decision on the rules, modalities and procedures for the mechanism established by Article 6, Paragraph 4, of the Paris Agreement

APPENDIX 3: Draft Conference of the Parties serving as the Meeting of The Parties to the Paris Agreement decision on the work programme under the framework for non-market approaches referred to in Article 6, Paragraph 8, of the Paris Agreement 


\section{ABBREVIATIONS}

AOSIS Alliance of Small Island States

CDM Clean Development Mechanism

CER Certified Emission Reduction

CMA Conference of the Parties serving as the meeting of the Parties to the Paris Agreement

$\mathrm{CO}_{2} \mathrm{e} \quad$ carbon dioxide equivalent

COP Conference of the Parties

ICAO International Civil Aviation Organization

IMO International Maritime Organization

IPCC Intergovernmental Panel on Climate Change

ITMO internationally transferred mitigation outcome

LDC least developed countries

LMDC like-minded developing countries

NDC nationally determined contribution

SBSTA Subsidiary Body for Scientific and Technological Advice

UNFCCC United Nations Framework Convention on Climate Change 


\section{BACKGROUND}

1. Article 6 of the Paris Agreement is generally known as the "markets article." While broadly correct, it could more properly be called the "article on international cooperation." A number of provisions address specific instances of cooperation that involve using internationally transferred mitigation outcomes (ITMOs) toward meeting nationally determined contributions (NDCs), and creating a framework for building international carbon markets and a framework for non-market approaches to international cooperation. These provisions are as follows:

(i) Cooperative approaches that involve the use of internationally transferred mitigation outcomes (para. 6.1). This paragraph covers the general concept that Parties may choose, on a voluntary basis, to cooperate in the implementation of their NDCs. Article 6 is meant to cover all existing cases of cooperation, and others that may emerge in the future. It is important to mention that cooperation is noted, acknowledged, and recognized, rather than approved by a body under the Paris Agreement. This reinforces the decentralized and bottom-up nature and ethos of the Paris Agreement governance.

(ii) Cooperation through the transfer of mitigation outcomes (para. 6.2-6.3). These paragraphs cover the specific case where Parties cooperate through the ITMOs that are to be used toward NDCs. In the case of such cooperation, Parties need to observe the accounting guidance from the Conference of the Parties serving as the meeting of the Parties to the Paris Agreement (CMA). These paragraphs are not about markets, but about a framework for accounting for transfers between Parties. What is particularly important about this provision is that these ITMOs can be produced through any mitigation approach (mechanism, procedure, or protocol), not necessarily operating under the authority of the Conference of the Parties (COP). Essentially, only the Parties involved need to agree. In these paragraphs, the Paris Agreement itself sets no limits on what constitutes an ITMO, and this broad scope is supported by the "institutional memory" of the Paris Agreement negotiations. Any limits that may be introduced will essentially be an additional boundary or limitation that Parties to the Paris Agreement will need to agree on in the operationalization of Article 6, but have no "hook" in the current text of the Paris Agreement.

(iii) Mechanism to contribute to mitigation and support sustainable development (para. 6.4-6.7). These paragraphs refer to the establishment of a mechanism that will produce mitigation outcomes and support sustainable development, and that operates under the authority of the COP. The mitigation outcomes produced can then be used to fulfill the NDC of another Party. A key issue currently under debate is whether the scope of these paragraphs is limited to a mechanism like the Clean Development Mechanism (CDM), or if it is much broader in scope, (i.e., including programmatic and sectoral scales). The interpretation that the new mechanism can have a broader scope seems to receive support from the historical evolution of the text, from submissions made so far under Article 6 under the Subsidiary Body for Scientific and Technological Advice (SBSTA) on Article 6, as well as from positions expressed in formal and informal discussions. Another key issue under discussion is whether or not Article 6.4 emission reductions should be treated and transferred as ITMOs under Article 6.2. This would make Article 6.4 subject to Article 6.2 guidance.

(iv) Establishment of a framework for non-market approaches (para. 6.8-6.9). Para. 6.8 outlines the establishment of a framework for non-market approaches. What this part of Article 6 covers is still largely undefined, although some clarity is starting to emerge. One intended focus of attention seems to be the coordination of different non-market 
approaches to cooperation. Other ideas that have been put forward concern the need for complementarity between Articles 6.8 and 6.9 and other provisions of the Paris Agreement, including Articles 6.2 to 6.7, to ensure the sustainability of mitigation approaches and address issues of global competitiveness in a cooperative manner, hence a connection to Article 4.15 of the Paris Agreement which concerns the impacts of response measures. Parties have discussed a work program to be agreed alongside decisions for Article 6.2 and 6.4. However, the content of the work program is yet to be agreed upon.

2. Like all other international agreements, the Paris Agreement, including Article 6, contains constructive ambiguities, which allowed countries at the 21st meeting of the COP (COP 21) in Paris in December 2015 to sign the agreement and defer negotiations on controversial issues. To make the Paris Agreement operational, these ambiguities need to be resolved. When in doubt, Parties should nominally go back to a series of principles that will allow for consistent decisions. Some of the principles that need to be recalled may include the following:

(i) The ethos of the Paris Agreement is bottom-up governance, with strong transparency provisions.

(ii) The building blocks of the Paris Agreement are the NDCs, for which ambition should increase over time.

(iii) The Paris Agreement is unitary, that is, Article 6 cannot be seen in a vacuum but must be understood as part of the whole agreement, having strong links with many other articles, especially Articles 4, 13, and 15.

(iv) Article 6 itself must be seen as unitary, that is, its provisions cannot be considered in isolation and work in silos. These provisions were included in Article 6 for a purpose, and the Parties understood that they represented different options that the Parties could avail themselves of, if and when they wished to cooperate.

(v) Article 6 and markets have particularities that must be kept in mind. While political solutions and compromises may work for many Paris Agreement issues (transparency, finance, compliance, etc.), markets will work only if the solutions create the conditions for a well-functioning and transparent market, where assets can be tracked and there is good price discovery. Markets depend on the participation of the private sector, which has options for directing financial flows and making investments. The CDM, which took many years, and a great deal of effort, to fix, should provide a warning signal.

There are few technical issues at this level of discussions. Most issues are political, and will require political leadership, political solutions, and especially political choices, whereas the technical issues could be mandated to work programs under SBSTA.

\section{ISSUES}

\section{A. Outcomes of the 24th Conference of the Parties}

3. The outcomes of the last round of negotiations at the 50th meeting of the Subsidiary Body for Scientific and Technological Advice (SBSTA 50) in Bonn, Germany, and the key challenges ahead, must be discussed and understood in the context of what led to the round of negotiations being held. 
4. The work on developing the Paris Agreement rule book was a work program mandated under decision 1/CP.21 at COP 21. Parts of the work program were assigned to different bodies under the Conference of the Parties serving as the meeting of the Parties to the Paris Agreement (CMA). In the case of Article 6, the work was mandated to the SBSTA under decision 1/CP.21:

(i) Para. 37 of the decision, regarding Article 6.2:

Requests the SBSTA to develop and recommend the guidance referred to under Article 6, paragraph 2, of the Agreement for consideration and adoption by the CMA at its first session, including guidance to ensure that double counting is avoided on the basis of a corresponding adjustment by Parties for both anthropogenic emissions by sources and removals by sinks covered by their nationally determined contributions under the Agreement....

(ii) Para. 38 of the decision, regarding Article 6.4:

Recommends that the CMA adopt rules, modalities, and procedures for the mechanism established by Article 6, paragraph 4, of the Agreement...

(iii) Para. 40 of the decision, regarding Article 6.8:

Also requests the SBSTA to undertake a work program under the framework for nonmarket approaches to sustainable development referred to in Article 6, paragraph 8, of the Agreement, with the objective of considering how to enhance linkages and create synergy between, inter alia, mitigation, adaptation, finance, technology transfer and capacity building, and how to facilitate the implementation and coordination of nonmarket approaches....

5. Post-Paris work took off in May 2016 when the SBSTA asked Parties and observer organizations to make submissions ${ }^{1}$ on their views related to guidance for the Article 6 items, ahead of the 22 nd session of the COP (COP 22). As is often the case after a major gathering such as COP 21 in Paris, the meetings that follow tend to be more low-key. This was true of COP 22 in Marrakech, Morocco, where Parties in the area of Article 6 made a cautious start, reverted to old positions, and were not ready to offer concrete suggestions. However, Parties identified key issues and started to exchange ideas on how best to address them. ${ }^{2}$

6. COP 23 (SBSTA 47) in Bonn focused on the Talanoa Dialogue ${ }^{3}$ and on the development of the Paris Agreement rule book. Article 6 negotiations at this COP benefited from a considerable amount of preparatory work, including a pre-session workshop on Article 6. Discussions resulted in a mandate for the Chair to prepare informal documents for the three main sections of Article 6.

7. In December 2018 at COP 24 in Katowice, Poland, all chapters of the Paris Agreement rule book were completed and agreed on by the Parties, except for Article 6 (also the last article to be agreed on in Paris). This would indicate that some Parties may not prioritize the use of markets to address climate change, while others continue to find the use of markets a questionable approach. It also signals deep divisions-sometimes philosophical-among supporters of markets, regarding the approaches to be adopted, and the final design of the regulatory framework. The question that needs to be taken from this is, who are the champions for Article 6?

1 UNFCCC. 2016. Report of the Subsidiary Body for Scientific and Technological Advice on its forty-fourth session. Session meeting and report prepare for SBSTA 44. Bonn. 16-26 May. https://unfccc.int/resource/docs/2016/sbsta/eng/02.pdf.

2 International Emissions Trading Association. 2016. COP 22 Summary Report. Marrakech. 20 November. https://www.ieta.org/resources/UNFCCC/COP22/COP22WRAP_FINAL.pdf.

3 The Talanoa Dialogue was mandated by the Parties to the United Nations Framework Convention on Climate Change (UNFCCC), to take stock of the collective global efforts to reduce the emissions of greenhouse gases, in line with the goals of the Paris Agreement. The Talanoa Dialogue was launched at COP 23 under the Presidency of the Republic of Fiji. UNFCCC. Process and Meeting. 2018 Talanoa Dialogue Platform. https://unfccc.int/process-and-meetings/the-paris-agreement/the-paris-agreement/2018-talanoa-dialogue-platform. 
8. When the Katowice rule book "package" was released by the Polish Presidency of COP 24 with what it had hoped was a "landing zone," it contained a number of chapters in the form of so-called "L-documents." "While all of these were met with approval as a basis for negotiations, even if grudging at times, the three L-documents that covered Article 6 were quickly withdrawn, as it was clear that they would not receive enough support.

9. This lack of support was due not only to fundamental issues in these documents that the Parties could still not agree on, but also to the large number of elements punted to the 2019 work program, making the rule book on Article 6 unacceptably thin on key elements. Instead of these three L-documents, a "procedural decision"5 was adopted that contained three elements:

(i) The decision stated that work would continue in 2019 under the SBSTA with the aim of completing the Article 6 rule book at COP 25.

(ii) Two documents were noted for consideration as part of the continued negotiations: the text at the end of SBSTA 49 (the L-documents [footnote 4]), and the Presidency text of 14 December 2019. ${ }^{6}$ The SBSTA text can be seen as being more Party-driven, as it includes all Party options. The Presidency text of December 14, on the other hand, is by necessity, an attempt at a landing zone. It therefore eliminates options and moves many provisions to the 2019 work program.

(iii) The decision also made it clear that the provisions that were inserted at the last minute in Katowice in para. 77(d) of the Transparency decision 18/CMA.1, which provides for elements of reporting for Article 6, were "without prejudice" to the outcome of negotiations under Article 6. This has led to another round of interpretations with some Parties understanding this clarification to mean that Article 77(d) was a "placeholder," and that its final content would be determined by the outcomes of the Article 6 negotiations, and that the Article 6 negotiations were in no way constrained by whatever was contained in Article 77 (d). Others chose to refer to Article 77(d) as a done deal, and the need to adapt the outcomes of upcoming Article 6 negotiations to what is currently in Article 77(d) as a given.

10. In the United Nations Framework Convention on Climate Change (UNFCCC) process, Parties seem to like to adopt the philosophy that "nothing is agreed until everything is agreed." However, in their efforts to reach an agreement on the Article 6 rule book at COP 24, Parties seemed to have worked out what some take as tentative language on a number of issues, including those related to governance and transparency.

\footnotetext{
4 L-documents are official documents with distribution limited "to those likely to be immediately interested in the work of the body concerned." Draft texts can be found at UNFCCC. 2018. Matters Relating to Article 6 of the Paris Agreement: Guidance on Cooperative Approaches Referred to in Article 6, Paragraph 2, of the Paris Agreement. https://unfccc.int/documents/186331; UNFCCC. 2018. Matters Relating to Article 6 of the Paris Agreement: Rules, Modalities, and Procedures for the Mechanism Established by Article 6, Paragraph 4, of the Paris Agreement https://unfccc.int/documents/186333; and UNFCCC. 2018. Matters Relating to Article 6 of the Paris Agreement: Work Programme Under the Framework for Non-Market Approaches Referred to in Article 6, Paragraph 8, of the Paris Agreement. https://unfccc.int/documents/186334.

5 UNFCCC. 2018. Report of the Conference of the Parties serving as the meeting of the Parties to the Paris Agreement on the third part of its first session, Addendum 1. Part two: Action taken by the Conference of the Parties serving as the meeting of the Parties to the Paris Agreement. Session and meeting reports prepared for COP24. Katowice. 2-15 December. https://unfccc.int/sites/default/files/resource/cma2018_03a01E.pdf.

6 UNFCCC. 2018. The Katowice Texts: Proposal by the President. Draft negotiating texts prepared for COP 24. Katowice. 2-14 December. https://unfccc.int/sites/default/files/resource/Katowice\%20text\%2C\%2014\%20Dec2018_1015AM.pdf.
} 
11. The text in Box 1, which relates to transparency provisions, was a last-minute insertion in the Katowice decision with the strong caveat "that information provided in a structured summary referred to in decision -/CMA.1, para. 77(d), 23 is without prejudice to the outcomes on these matters" (9 [iii]). ${ }^{7}$

\section{Box 1: Transparency Decision Relating to Article 6}

The Transparency decision, which is part of the Katowice rulebook agreed on, includes the section "Information necessary to track progress made in implementing and achieving its nationally determined contribution under Article 4 of the Paris Agreement." Article 77(d) has provisions that are controversial because they are seen by some to prejudge the outcome of the Article 6 decision. The provisions read as follows:

Each Party shall provide the information referred to in paragraphs 65-76 above in a structured summary to track progress made in implementing and achieving its NDC under Article 4, including:

Each Party that participates in cooperative approaches that involve the use of internationally transferred mitigation outcomes towards an NDC under Article 4, or authorizes the use of mitigation outcomes for international mitigation purposes other than achievement of its NDC shall also provide the following information in the structured summary consistent with relevant decisions adopted by the CMA on Article 6 and -/ CMA.1:

(i) The annual level of anthropogenic emissions by sources and removals by sinks covered by the NDC, on an annual basis reported biennially.

(ii) An emissions balance reflecting the level of anthropogenic emissions by sources and removals by sinks covered by their NDC adjusted on the basis of corresponding adjustments undertaken by effecting an addition for ITMOs firsttransferred/transferred and a subtraction for ITMOs used/acquired, consistent with decisions adopted by the CMA on Article 6.

(iii) Any other information consistent with decisions adopted by the CMA on reporting under Article 6.

(iv) Information on how each cooperative approach promotes sustainable development; and ensures environmental integrity and transparency, including in governance; and applies robust accounting to ensure inter alia the avoidance of double counting, consistent with decisions adopted by the CMA on Article 6.

$\mathrm{CMA}=$ Conference of the Parties serving as the meeting of the Parties to the Paris Agreement, ITMO = internationally transferred mitigation outcome, NDC = nationally determined contribution.

Source: UNFCCC. 2018. Report of the Conference of the Parties serving as the meeting of the Parties to the Paris Agreement on the third part of its first session, Addendum 2. Part two: Action taken by the Conference of the Parties serving as the meeting of the Parties to the Paris Agreement. Session and meeting reports prepared for COP24. Katowice. 2-14 December. pages 18-52. https://unfccc.int/sites/default/files/resource/CMA2018_03a02E.pdf.

7 UNFCCC. 2018. Draft Text on SBSTA 49 agenda item 11(a) Matters relating to Article 6 of the Paris Agreement: Guidance on cooperative approaches referred to in Article 6, paragraph 2, of the Paris Agreement. Draft negotiating texts prepared for COP 24. Katowice. 2-14 December. https://unfccc.int/sites/default/files/resource/SBSTA49_11a_DT_v2.pdf. 


\section{B. Key Areas of Divergence}

12. As always, the post-mortem tries to determine why the work on Article 6 at COP 24 could not be completed. One of the key areas where consensus could not be reached was attributed to how to account the emission reductions resulted from the Article 6.4 mechanism within the NDC. Some Parties argued that there was no need to account within the NDC of the Host Country for any units issued from the Article 6.4 mechanism since any mitigation actions under Article 6.4 would be in addition to, or beyond, what was promised in the NDC. Another argument presented was that those undertaking such actions under Article 6.4 would primarily be private sector organizations, which would be financially rewarded for those actions. This would leave the Host Party with the obligation to backstop any units transferred-not an appealing prospect. However, some Parties saw very important flaws in this approach, and expressed great concern that it would lead to double counting.

13. Another issue raised by some Parties, which was also met with considerable opposition, was the proposal for a blanket transition of CDM projects, units, and protocols (methodologies, accreditation protocols, etc.) from the Kyoto Protocol to Article 6.4. This could be a way of ensuring regulatory continuity and the credibility of the UNFCCC process. However, other Parties feared that this would flood the market with Certified Emission Reductions (CERs), depress prices, and slow down climate action. It is not clear if the debate considered the dependence of many projects on carbon finance and that many CDM projects are vulnerable with continued carbon finance.

14. Building a house without a solid foundation is generally not a winning proposition, and yet it was not possible, and probably not desired by some Parties, to agree to a definition for an ITMO. The definition included possible redline issues for some Parties:

(i) The inclusion of greenhouse gas removal by sinks met with great opposition from some Parties and support from others under CDM, where afforestation and reforestation activities are eligible for crediting (resulting in temporary credits), but are not in favor of crediting for Reducing Emissions from Deforestation and Forest Degradation or REDD+).

(ii) In the absence of a clear definition, the inclusion of avoidance ${ }^{8}$ creates significant problems for many Parties and negotiation groups, which fear that it may open the door to compensation for leaving hydrocarbons in the ground, as well as very shaky baselines.

(iii) The metric in which ITMOs could be expressed was also a contentious issue, with many Parties insisting on carbon dioxide equivalent $\left(\mathrm{CO}_{2} \mathrm{e}\right)$ as the only logical metric. Others saw a $\mathrm{CO}_{2}$ e-only approach as chipping away at the nationally determined nature of NDCs, and forcing them to express their progress toward NDCs through inventories, instead of indicators and metrics of their own choosing. For these groups, this was a departure from what they considered to be a fundamental agreement reached in Paris, that of making NDCs the building block of the Paris Agreement.

(iv) There were other issues in the tentative definition section covering ITMOs in the SBSTA text-subtle issues perhaps, but seen by some as nudging Parties toward expressing their NDCs in $\mathrm{CO}_{2}$ e terms. For illustration purposes, the SBSTA text contains this provision:

"Internationally transferred mitigation outcomes (ITMOs)" are to be measured in metric tonnes of carbon dioxide equivalent $\left(\mathrm{CO}_{2} \mathrm{e}\right)$ in accordance with the methodologies and

\footnotetext{
8 Avoidance can mean stopping emissions from occurring, e.g., CDM methodology AMS-III.F: Avoidance of methane emissions through composting. It can also cover a solution (product or service) that enables the same function to be performed with significantly less greenhouse gas emissions (referred to as Scope 4 in greenhouse gas reporting). In this case, a common understanding is that it refers to the proposal by Ecuador.
} 
common metrics assessed by the Intergovernmental Panel on Climate Change (IPCC) and adopted by the CMA and/or in other metrics [determined by the participating Parties, consistent with the national determined contributions (NDCs) of the participating Parties."

This provision seems to limit transfers in metrics other than $\mathrm{CO}_{2}$ e to only Parties that have the NDC expressed in the same metric, which is seen as an unjustified restriction by many Parties.

(v) A key issue, that of what gets to be correspondingly adjusted to avoid double counting, and the timing of that adjustment, was tentatively resolved at COP 24 through menus, by providing Parties with the following choices:

a) One option was for Parties to express an inventory-adjusted number in $\mathrm{CO}_{2}$ e. This was the choice of a large number of Parties.

b) Another option was for Parties to adjust what many called a "buffer account." This is a misnomer; a better name is a netting account. This was intended as a real-time corresponding adjustment, starting at zero, every time there is a transfer. The number in the buffer account is only a means to an end, as it would be used at the end of "every year [or] every [2] years" to adjust the NDC, and measure progress toward the NDC. This would ensure total regulatory transparency. This approach is thought to also allow progress toward the NDC to be measured through any indicator (and metric) chosen by any Party, including through $\mathrm{CO}_{2}$ e. The buffer account concept applies to any metric but the real understanding must come the choice between NDC accounting or emissions accounting. They could be the same but do not have to be the same.

(vi) The whole cycle of tracking transfers, making corresponding adjustments, reviewing, and registering was not well explained by Parties that had earlier provided explanatory text. The concepts, flow of ideas, and text were thus difficult for many Parties to understand and in turn, state clear positions as well as agree on the draft text.

(vii) In relation to the CDM transition to the Article 6.4 mechanism, many Parties had clear concerns. The concerns centered on the impact that a large number of CERs, and possibly reduction-producing projects coming from the CDM into Article 6.4, would have on the new post-2020 carbon market. The sheer number of transferred CERs (and their quality) could be seen as leading to a new collapse in carbon prices, and a significant disincentive for new mitigation action. Others would argue for the need to ensure the credibility of a regulatory-catalyzed action under the overall umbrella of the UNFCCC, through the Kyoto Protocol or the Paris Agreement.

(viii) One issue that relates to the Article 6.4 mechanism is whether or not Article 6.4 mitigation outcomes should be undergoing the first transfer at issuance under the Article 6.2 rules. The argument is that the first issuance comes from activities that are additional to the NDC and as such, a corresponding adjustment is not justified and in essence makes them lose control of the NDC. Another issue also related to the Article 6.4 implementation is

9 The draft text on SBSTA 50 agenda item 11(a), Matters relating to Article 6 of the Paris Agreement: Guidance on Cooperative Approaches referred to in Article 6, paragraph 2, of the Paris Agreement, Version 2, of 26 June has more details. https://unfccc.int/sites/default/files/resource/sbsta50.DT_.i11a2.pdf. 
how to address overall mitigation to global emissions. Two issues emerge here: one is the seemingly voluntary nature of the concept and the other is how to operationalize it, e.g., by baseline setting.

15. The preceding list contains many of the important points of contention and serves to illustrate the breadth and depth of the unresolved issues. The statement sometimes heard in the corridors that "if we only had a few more hours, we could have nailed it in Katowice" may not seem to square with reality. Not all of the issues listed were redline issues, but there were enough of such issues to make compromise unrealistic. Given the fact that some key issues were not to be finalized in Katowice but were being pushed to the 2019 work program of SBSTA, this led to a sense that there was not enough in the Katowice text proposed by the Presidency for an agreement on the Article 6 rule book: why agree on these limited provisions when many of the key issues to be resolved were being pushed forward anyway?

\section{Outcomes of the 5oth meeting of the Subsidiary Body for Scientific and Technological Advice}

16. It can be argued that the main positive outcome of SBSTA 50 was the emergence of a new text, ${ }^{10}$ replacing the two texts forwarded from Katowice to SBSTA 50 (the L-documents developed by SBSTA and the Presidency compromise proposal). While the new text is not radically different, as most of its provisions are roughly the same as those found in the Katowice texts, it represents progress in two ways:

(i) It is better articulated and presents the options more clearly.

(ii) Parties seem to take real ownership, and this bodes well for the upcoming session in Madrid.

17. However, a consensus was not reached regarding inter-session work, so there will be no technical paper from the UNFCCC secretariat and no technical workshop between now and COP 25.

18. Other developments resulting from SBSTA 50 should be highlighted, as they are relevant to future negotiations and will affect the probabilities of a positive outcome at COP 25.

\section{Organizational Matters}

19. SBSTA 50 saw a number of organizational changes:

(i) The SBSTA Chair conducted Article 6 negotiations in coordinated leadership with the co-facilitators who led the informal discussions.

(ii) There was a new team of co-facilitators. Like any team, they brought to the table their combined skills and balance, both professionally and personally. The combined leadership and dynamic of the team plays an important role in addressing substantive issues, as well as through the image they project to the room.

\footnotetext{
10 UNFCCC. 2019. Guidance on Cooperative Approaches Referred to in Article 6, Paragraph 2, of the Paris Agreement. Paper prepared for the 50th Meeting of the Subsidiary Body for Scientific and Technological Advice. Bonn, Germany. 17-27 June. https://unfccc.int/sites/default/files/resource/sbsta2019_L.09E.pdf; UNFCCC. 2019. Rules, Modalities and Procedures for the Mechanism Established by Article 6, Paragraph 4, of the Paris Agreement. Paper prepared for the 50th Meeting of the Subsidiary Body for Scientific and Technological Advice. Bonn, Germany. 17-27 June. https://unfccc.int/sites/default/files/resource/sbsta2019_L.10SE.pdf; and UNFCCC. 2019. Work Programme Under the Framework for Non-Market Approaches Referred to in Article 6, Paragraph 8, of the Paris Agreement. Paper prepared for the 50th Meeting of the Subsidiary Body for Scientific and Technological Advice. Bonn, Germany. 17-27 June. https://unfccc.int/sites/default/files/resource/sbsta2019_L.11E.pdf.
} 
(iii) Heads of delegations also became involved. While they were present in the Article 6 room, they were also present in rooms where the issues being debated had, or were perceived to have, a tactical connection to Article 6. That was true of the Contact Group on Response Measures and Transparency.

20. All this led to increased attention to Article 6 negotiations, which was felt in the dynamic of the room, as well as in the political support visibly provided for positions taken by different negotiators. This, in some cases, led to more vocal reactions, and hardening of positions. Whether this presence at an early stage ahead of COP 25 will prove to be positive is obviously an open question. Higher-level presence and involvement bring the possibility (or threat) of a political solution. In Katowice, so-called technical negotiators were unable to agree, as a result. Political solutions are unpredictable, sometimes necessary, but not always the best for a topic such as markets (Section 1.2, Principle 5). This points to the necessity for Article 6 negotiators to identify issues of principle and raise these with their ministers to unlock negotiations on operational matters under SBSTA.

21. A new set of countries are starting to work together on certain issues, such as, corresponding adjustments for Article 6.4 issuance, metrics, corresponding adjustments for Article 6.2, CDM transition, and, to some degree, the use of ITMOs for purposes other than NDCs. This group also backed procedural and process issues, such as in their rejection of inter-session work on technical papers and meetings on Article 6.

22. While clearly not a formal alignment, this mutual support group nevertheless broke the isolation for some Parties on critical issues and ensured that this group could not be overruled. These views, and grouping, were also present at COP 24, but the perception was of a much more ad hoc effort at that time, less well-understood, and with less clear positions and willingness to defend and provide mutual support.

23. Recurring issues. A third outcome of SBSTA 50 that must be recognized was the re-emergence of some issues that were thought to have been resolved in Katowice:

(i) Corresponding adjustment. Approaches such as corresponding adjustments through a budgeting approach had been abandoned in the final hours of COP 24, only to be reintroduced at SBSTA 50 in Bonn.

[A budget basis, by effecting an addition or subtraction to its quantification of the greenhouse gas emissions level corresponding to its NDC. The corresponding adjustment shall be effected through a subtraction for ITMOs transferred and an addition for ITMOs acquired. $]^{11}$

(ii) Accounting for single-year nationally determined contributions. Issues such as the use of a menu of options allowing Parties to choose the accounting approach when dealing with single-year NDCs have now been re-opened with the introduction of a default option that Parties would have to adopt if they are unable to indicate a choice:

[In its initial report pursuant to section VII. A (initial report), a participating Party may identify its method for corresponding adjustments from the following list of methods: \{list required\}, to be applied consistently throughout the NDC implementation period. If a Party does not identify the method, the default method of [for a multi-year NDC, an indicative multi-year emissions trajectory; for a single year NDC, an average annual amount of ITMOs] shall be applied by the Party. $]^{12}$

11 Footnote 7. p. 5, para. 12(a).

12 UNFCCC. 2019. Draft Text on SBSTA 50 agenda item 11(a) Matters relating to Article 6 of the Paris Agreement: Guidance on cooperative approaches referred to in Article 6, paragraph 2, of the Paris Agreement (Version 1 of 25 June 07:00 hrs). Draft negotiating text prepared for SBSTA 50. Bonn. 17-27 June. p. 6, para. 21. https://unfccc.int/sites/default/files/resource/SBSTA50.DTi_.11a_1.pdf 
(iii) Carbon dioxide equivalent primacy. The bracketing of the whole ITMO definition paragraph to include the approach of referring to " $\mathrm{CO}_{2} \mathrm{e}$ and other metrics," would indicate a hardening of positions and a challenge to the general approach adopted in the Katowice texts, which appeared to give special recognition to the $\mathrm{CO}_{2} \mathrm{e} /$ inventory-based approach, beyond that accorded to other metrics and inventories. The thinking, in this case, seems to be that the provision "metrics agreed by both Parties" would automatically include $\mathrm{CO}_{2}$ e." A special reference to $\mathrm{CO}_{2}$ e is seen as either redundant or giving the $\mathrm{CO}_{2}$ e metric a special prominence when compared with other metrics in NDCs.

[Be measured in metric tons of carbon dioxide equivalent $\left(\mathrm{tCO}_{2} \mathrm{eq}\right)$ in accordance with the methodologies and common metrics assessed by the IPCC and adopted by the CMA, and/or in other metrics determined by participating Parties consistent with the NDCs of the participating Parties.] $]^{13}$

\section{Box 2: Initial Options from the 24the Conference of the Parties Texts}

\section{Option A: Budget-Based Corresponding Adjustment}

The first option is budget-based, and involves applying the corresponding adjustment through addition to or subtraction from its quantification of the GHG emissions level corresponding to its NDC.

\section{Option B: Emissions-Based Corresponding Adjustment}

The second option is emissions-based, by applying the corresponding adjustment through effecting addition to or subtraction from the emissions and removals covered by its NDC, as derived from its national inventory report.

\section{Option C: Buffer Registry-Based Corresponding Adjustment}

The third option is a buffer-registry (netting account) basis by applying the corresponding adjustment through effecting an addition or subtraction from a starting point of a zero balance, with a resulting balance that reflects net transfers and acquisitions and is applied to the NDC in accordance with guidance under Article 4, paragraph 13.

\section{Option D: Emissions Reductions-Based Corresponding Adjustment}

This option applies the corresponding adjustment by adding to or subtracting from the total quantity of emission reductions achieved.

GHG = greenhouse gas, NDC = nationally determined contribution.

Source: UNFCCC. 2018. Draft Text on SBSTA 49 agenda item 11(a) Matters relating to Article 6 of the Paris Agreement: Guidance on cooperative approaches referred to in Article 6, paragraph 2, of the Paris Agreement. Draft negotiating texts prepared for COP 24. Katowice. 2-14 December.

https://unfccc.int/sites/default/files/resource/SBSTA49_11a_DT_v2.pdf.

13 Footnote 12, p. 3, para. 1(a)(iii). 


\section{Box 3: Options for Corresponding Adjustments for Single-Year Nationally Determined Contributions}

The Party applies a corresponding adjustment for the same year as the single-year NDC, that is representative of the first transfer, transfer, acquisition, and/or use of ITMOs by that Party over the NDC implementation period by:

(i) calculating a multi-year emissions trajectory for the NDC implementation period consistent with the achievement of its NDC and applying a corresponding adjustment for each year covered by this emissions trajectory;

(ii) calculating an average amount of ITMOs first transferred, transferred, acquired and/or used over the NDC implementation period and applying a corresponding adjustment equal to this average amount for the same year as the single year NDC; or

(iii) applying corresponding adjustments, for ITMOs used toward its NDCs, in the single year of its NDC, on the basis of ITMOs it has transferred and acquired in that year, but also applies corresponding adjustments to the same basis for the preceding years of the period over which the NDC is implemented.

ITMO = internationally transferred mitigation outcome, NDC = nationally determined contribution.

Source: UNFCCC. 2019. Draft Text on SBSTA 50 agenda item 11(a) Matters relating to Article 6 of the Paris Agreement: Guidance on cooperative approaches referred to in Article 6, paragraph 2, of the Paris Agreement [Version 2 of 26 June 16:45:00hrs (edited)]. Draft negotiating text prepared for SBSTA 50. Bonn. 17-27 June.

https://unfccc.int/sites/default/files/resource/SBSTA50.DT_.i11a\%20clean.pdf.

24. Emerging issues. A fourth development that needs to be highlighted is the emergence of new issues, or the stronger emphasis on provisions that may not have been emphasized, or well-understood, in Katowice. This category would include the following:

(i) Use of internationally transferred mitigation outcome for purposes other than nationally determined contributions. Most would see this as a provision allowing the use of ITMOs from Article 6.2 and units from Article 6.4 (including CERs transferred from the CDM) for compliance with International Civil Aviation Organization (ICAO) measures, and possibly International Maritime Organization (IMO) compliance. This is a provision that most Parties felt was well-understood and accepted, with concerns focused mostly on ensuring that provisions would be put in place to avoid double counting between the Paris Agreement and ICAO. However, at SBSTA 50, some Parties took strong positions to the effect that ITMOs were solely for NDC use, and that nothing in the Paris Agreement would justify the transfer of ITMOs between the Paris Agreement and ICAO or IMO.

(ii) Design of the Article 6.4 mechanism. Parallels have often been drawn between the CDM and the new Article 6.4 mechanism. Some Parties referred to the Article 6.4 mechanism as the Sustainable Development Mechanism, a revival or continuation of the CDM, with possible improvements. While some insist on clear options for significant decentralization provisions. Under these decentralizing provisions, the Article 6.4 mechanism would depart from the CDM governance by allowing certain functions, such as the development and approval of baselines, the accreditation of Designated Operation Entities, and crediting periods to be fulfilled by the Host Country, under guidelines and some level of supervision by the CMA-created Article 6.4 mechanism Supervisory Body. While this effort toward 
greater decentralization will find sympathy and support, many Parties cling to the vision of a Paris Agreement, which provided for decentralized cooperation under Article 6.2, yet find reassurance in centralized governance for cooperation under Article 6.4.

(iii) Unilateral action under Article 6.2. The CDM started as a collaborative mechanism, and it took some effort and serious political negotiation to achieve acceptance of "unilateral CDM." In a similar vein, Joint Implementation started with the concept of bilateral implementation but to a large extent resulted in unilaterally developed projects with an offtake agreement with a bilateral partner. There have not been any significant discussions on the nature of Article 6.2 and the creation of ITMOs. For many, ITMOs are mitigation outcomes created by one Party, which then become ITMOs when transferred internationally to another Party. The creation of mitigation outcomes that would later become ITMOs was largely seen as the preserve of Parties that undertook the first transfer. However, others were of the view that bilateral cooperation was required in the creation and first transfer of ITMOs (including standards for such mitigation outcomes). Many that support unilateral creation, saw the concept of bilateral creation as the "thin edge of the wedge" and the start of "interference" in their NDCs.

(iv) Safeguards and limits. This issue received more attention and airtime at SBSTA 50 than expected, and therefore merits mention in this paper. Several Parties have proposed subjecting international transfers under Article 6 to quantitative limits. Such limits are seen as a way not only to address environmental integrity concerns but also to pursue other policy objectives, such as ensuring that a minimum portion of mitigation action takes place domestically. The Kyoto Protocol contains provisions for a commitment period reserve to limit the number of units that could be traded:

Each Party included in Annex I shall maintain, in its national registry, a commitment period reserve which should not drop below $90 \%$ of the Party's assigned amount ... or $100 \%$ of five times its most recently reviewed inventory, whichever is the lowest. ${ }^{14}$

The Kyoto Protocol also refers to supplementarity, which is the number of international units that a Party could use to meet its Kyoto Protocol commitments. The presence of a Safeguards chapter in the Article 6 rule book therefore cannot be a major surprise, except that in the case of the Paris Agreement there are no budgets, and a great variety of NDCs. This will make the definition of safeguards much more challenging, especially when it comes to defining them in terms of outgoing transfers. Provisions referring to human rights, response measures, and price fluctuations are likely to meet with stiff opposition. Provisions that may gain some traction but are unlikely to have full definition at COP 25, may address carryover, supplementarity, and transfer limits. Issues around unilateral measures and discriminatory practices have also received early signals of opposition, as they are seen by many Parties as connected to the World Trade Organization (WTO), and not part of the UNFCCC discussions.

\section{E. $\quad$ Reflections on Article 6.8}

25. Article 6.8, the non-market approaches part of Article 6, is seen both as the least advanced topic and, at the same time, a critical part of the Madrid discussions, if a positive outcome is to emerge in December 2019.

\footnotetext{
14 Footnote 1, p. 19, para. 6.
} 
26. While there are a number of chapters in the Article 6.8 draft text from SBSTA $50,{ }^{15}$ the most important ones would seem to address two elements: the governance of the framework and modalities, and the work program that would be undertaken.

27. Discussions of governance options at this stage revolve around the desire of some Parties to make a decision at COP 25, as against the aim of having a permanent body, forum, or task force, which would meet in conjunction with the Subsidiary Body sessions. Others would like to postpone the governance decision to COP 26 in 2020. This is the usual developed-developing country split and brings with it painful memories of similar discussions under Response Measures, with a political decision in the end.

28. Associated with the framework is the issue of Modalities. While some modalities refer directly to issues such as papers, submissions, and workshops, others are less defined and potentially more ambitious, referring to:

The coordination, where needed, of the governance of the framework referred to in section III above (governance of the framework) (hereinafter referred to as the A6.8 governance) and relevant bodies, institutional arrangements, and processes under the Convention, the Kyoto Protocol and the Paris Agreement related to, inter alia, mitigation, adaptation, finance, technology development and transfer, and capacity building. ${ }^{16}$

29. Finally, the issue of the work program, referring to issues that some Parties may find challenging, is likely to be the most contentious. Activities such as lessons learned and case studies are not expected to encounter stiff opposition. On the other hand, the development of tools "for addressing possible negative social and economic impacts of activities under Article 6"17 is unlikely to be met with unanimity.

30. The discussion has undertones of other politically contentious discussions, with response measures coming to mind as a fresh example. The challenge lies in having to resolve Article 6.8 at COP 25 , at the same time as the rest of the Article 6 rule book. The level of maturity of negotiations points to the need for some very intense discussions, without the luxury of time.

\section{WAY FORWARD TO COP 25}

31. The issue of climate change is not only a defining issue, but also one that needs the mobilization of significant resources. In this, Article 6 of the Paris Agreement plays an important role as it provides the framework for the mobilization of non-public sector resources.

32. Article 6 negotiators and Parties should consider the consequences of a second failure to reach an agreement on the rule book for Article 6 in Madrid at COP 25. There are two main questions:

15 UNFCCC. 2019. Work Programme Under the Framework for Non-Market Approaches Referred to in Article 6, Paragraph 8, of the Paris Agreement. Draft conclusion prepared for SBSTA50. Bonn. 17-27 June. https://unfccc.int/sites/default/files/resource/sbsta2019_L.11E.pdf.

16 UNFCCC. 2019. Draft Text on SBSTA 50 agenda item 11(c) Matters relating to Article 6 of the Paris Agreement: Work programme under the framework for non-market approaches referred to in Article 6, paragraph 8, of the Paris Agreement (Version 2 of 26 June 14:30 hrs). Draft negotiating texts prepared for SBSTA 50. Bonn. 17-27 June. p. 5, para. 14(e). https://unfccc.int/sites/default/files/resource/SBSTA50.DT_.i11c.1_0.pdf.

17 UNFCCC. 2019. Draft Text on SBSTA 50 agenda item 11(a) Matters relating to Article 6 of the Paris Agreement: Guidance on cooperative approaches referred to in Article 6, paragraph 2, of the Paris Agreement [Version 2 of 26 June 16:45:00 hrs (edited)]. Draft negotiating texts prepared for SBSTA 50. Bonn. 17-27 June. p. 17, para. 73.

https://unfccc.int/sites/default/files/resource/SBSTA50.DT_.i11a\%20clean.pdf. 
(i) Would this affect the ability for international cooperation? In principle, the answer should be "no," as Parties do not need permission to cooperate. Article 6 itself states that "Parties recognize that some Parties may choose to cooperate." The ethos of the Paris Agreement is generally bottom-up, but that does not imply a free-for-all.

In the special case of Article 6.2 and cooperation, which includes ITMOs, Parties have to observe a series of "must" provisions, including observing accounting rules consistent with what the CMA approves. The open question is whether there is currently enough in Article 77(d) to allow Parties to use, account, and report on the use of ITMOs, should they choose to do so. Some Parties believe so, others are adamantly opposed.

With respect to Article 6.4, it is definitely not operational and cannot be used in its present state. The current situation leaves a significant hole for Parties that were counting on using this provision to cooperate, create mitigation outcomes, and transfer those outcomes to other Parties for use toward meeting their own NDCs. As the CDM cannot be used toward NDC fulfillment, there would be no instrument under UNFCCC governance that Parties can use. This may also create problems for Parties intending to use the output of Article 6 for ICAO purposes.

Article 6.8, which is at a much less mature stage of development, would also suffer, since there would be no governance for the framework, and no work program.

(ii) Could this endanger the environmental integrity of the Paris Agreement? The answer is probably "yes," as no rules may force, or provide no option for some Parties than to set up their own plurilateral arrangements and rules, and make these arrangements as transparent as possible. While it is likely that many of these arrangements would be set up in good faith and with the best intentions, what happens in reality could be far from ideal. In addition, the lack of international rules may lead to cutting corners, inconsistencies in accounting procedures, and the risk of double counting, among a few possible issues. Questions regarding the quality and accounting for large quantities of ITMOs will make an already complex situation even more complex.

33. A third question would be, what will be the impact of a no-outcome on the private sector? While difficult to predict, it is likely that when faced with regulatory uncertainty, private sector money will hesitate. It will want to know the compliance value of any mitigation outcomes it invests in, the reputational risks associated with it, and many other questions involved in such investment decisions. These money flows will seek regulatory reassurance by gathering around credible groups of Parties or multilateral institutions with the credibility, reputation, and capacity to put together quasi-regulatory frameworks. For governments, results-based climate finance concepts could work in the absence of a UNFCCC-regulated market, but this would also result in low political interest in the market, which could limit the opportunity of engaging the private sector at scale through global markets.

34. All this points to the need to ensure a positive outcome for Article 6 from COP 25. However, as always, there are potential stumbling blocks that need to be recognized and addressed. Some of them are related to substantive issues, while others have to do more with the negotiating process and the approach to it. 


\section{POTENTIAL OBSTACLES}

35. To solve problems, one must identify, recognize, and come to grips with the reality that they need to be addressed and there are multiple issues that need to be resolved. Some of them are redlines; others are "wannabe" redlines. There is a logical tree that requires some choices to be made to progress. This needs to be recognized and accepted, even if it does not imply final acceptance. It is very difficult, if not downright impossible, to discuss many aspects of ITMOs and Article 6.2 governance when Parties cannot agree on the definition of an ITMO-whether an ITMO is a ton, a unit, a net number, or a net quantity (among other possible options). Additionally, is $\mathrm{CO}_{2}$ e the only metric? Or is it only one of many metrics, or a "primus inter pares"? To make progress, issues of "principle" will be need to be identified and formulated in a manner that will appeal to, and allow policy makers-heads of delegations and ministers - to address them and provide the guidance that will allow Article 6 negotiators to focus on choices they can make: on operational matters.

36. There must be a differentiation between issues that have the potential of real impact and those that do not. The desire of large numbers of Parties to use only $\mathrm{CO}_{2}$ e as a metric is well-documented and finds logical basis in how the amount of $\mathrm{CO}_{2} \mathrm{e}$ in the atmosphere is the only outcome that matters to the environment. One issue that may need to be looked at is the number of NDCs with non- $\mathrm{CO}_{2}$ e metrics, and the likely willingness of Parties to transfer ITMOs in metrics other than $\mathrm{CO}_{2} \mathrm{e}$. Is this a real problem that may affect the environmental integrity of the Paris Agreement (because of double counting or wrong conversion factors), or is it simply a matter of principle, where some Parties see the NDC metrics and indicators of progress toward the NDC as their own prerogative under the Paris Agreement and resist a $\mathrm{CO}_{2} \mathrm{e}$-only outcome?

37. Other solutions may be as effective as regulatory provisions at the UNFCCC level. Certain issues are real obstacles, but the possibility of addressing them through non-regulatory means (e.g., market solutions) or regulatory approaches at levels other than the UNFCCC should be examined and considered. Parties, within the context of international trade rules, have the ability to use ITMOs toward their NDCs as they see fit or as a matter of fact, not at all. Therefore, the metrics used, and the commitment to undertake a corresponding adjustment, could become the object of a multiparty political agreement among some Parties during the transfer or use of ITMOs ("no corresponding adjustment, no use"). Similarly, some Parties may object to transferring ITMOs that would be used for purposes other than meeting NDCs.

38. While all issues are important to some Parties, some need to be solved in Madrid to operationalize the components of Article 6. For illustration purposes, under Article 6.4, some issues should be delegated to the soon-to-be-created Supervisory Board. The desire to solve most issues under the CMA is understandable, given the view that the workings of the CDM Executive Board became politicized. However, this does not bode well for the trust that Parties put in the Article 6.4 Supervisory Body.

39. Some critical and controversial issues that need to be addressed at COP 25 are outlined in the following section. The main criterion for their inclusion is the likelihood that making these decisions will support the operationalization of Article 6. There is no intent to downgrade issues that some Parties have a strong attachment to. As can be seen, many of these issues are interrelated.

40. The decision in Madrid needs to send the right signal to the markets and governments, especially as it comes with the reputational risk of double counting. The decision needs to ensure that the issues of principle are addressed and resolved, which will facilitate completion of all operational requirements for Article 6.2. Article 6.4 will require the establishment of the Supervisory Body, which will then allow the work on modalities and procedures to be completed. It is likely that the CDM transition will need to accompany these outcomes to ensure that this issue is addressed at the satisfaction of the Parties. 


\section{Overview of Key Issues}

\section{Definition of internationally transferred mitigation outcomes}

(i) Definition. A quantity, number, net transfer, or unit.

(ii) Metrics. $\mathrm{CO}_{2}$ e only, any metric decided by Parties, $\mathrm{CO}_{2}$ e or any metrics decided by Parties. A decision would address to a large degree what needs to be adjusted-an inventorybased number or a buffer account.

(iii) Removals. Are they accepted as ITMOs? Are sinks/REDD+ ITMOs?

(iv) Avoidance. Is it an ITMO? How is avoidance defined? What conditions would make avoidance acceptable?

(v) When does an Article 6.4 unit come under Article 6.2 governance and start following ITMOs rules: at first or at second transfer?

42. Transparency and information made available to different regulators. Does the CMA need to know about (not approve) each transfer? Is this information relevant only to the Parties involved, with the only information relevant to the CMA being the year-end net? A decision would solve the timing of corresponding adjustments - should it be done at every transfer using the buffer account, or at year-end using the net transfer number?

43. Corresponding adjustment. The timing of the adjustment, and what gets adjusted, will be largely decided by the metrics (para. 43 item [ii]), and what is seen as relevant to the CMA (para. 44).

44. Treatment of accounting for single-year nationally determined contributions. This is a critical issue as it will reassure investors of the value of their investments. The decision will essentially rest on whether a choice will be made on political and acceptability grounds, or on the basis of environmental logic. On the face of it, all options in the text from SBSTA 50 appear to have a large degree of subjectivity in them. Using averages, cumulative amounts, or a trajectory for emissions that took place outside the year of the NDC commitment would provide functionality and liquidity to the market, but little relevance to what the atmosphere actually saw in the commitment year. Using only the vintage year of the commitment will make for an illiquid market and not encourage action. In the end, it is a political decision, but one that needs to be consistent. A menu approach, while providing an easy way out, is not a solution that will ensure strong consistency, environmental integrity, and transparency.

45. Use of internationally transferred mitigation outcomes for purposes other than nationally determined contributions. This issue can be seen as critical for a number of Parties, which will want to have it elucidated before agreeing on an Article 6 rule book.

46. Article 6.4 units: are they created only within the nationally determined contribution only, or only beyond the nationally determined contribution? This also solves the issue under para. 43 item (i). This issue has been central to the avoidance of double counting and has become close to a litmus test. Having been so elevated, it is difficult to see how it would not be part of a package agreed in Madrid.

47. Article 6.4 Supervisory Body and rules of procedure, are important as they allow for the establishment of a Supervisory body and its operation. This in turn will also permit work to continue intersessionally by an establish body under the CMA and significant progress to be made in 2020. 
48. Governance of the Article 6.4 mechanism, including degree of decentralization of some functions from the Supervisory Body to the Host Country representatives is a significant decision as some Parties feel that renegotiating such issue, or reaching an outcome separately, after the establishment of the Supervisory Body and its rules of procedures, will a long and drawn-out process.

49. Methodology choices are a significant decision that needs to be made before the Supervisory Body is established. Parties feel that the CDM had shown that the regulatory process may become politicized, and reaching agreement on this topic, through the Supervisory Body is not something that will reach optimal outcome.

50. Overall mitigation in global emissions. This is a really significant issue for some Parties, including LDCs and AOSIS. The introduction of language that implies a strong optionality has certainly not been welcomed by these groups and will need to be resolved at COP 25.

51. Definition of the work program and governance of the framework are also issues that need to be addressed and are seen as thorny. A conclusion on Article 6.8 is needed to have a complete Article 6 package. A decision on the governance of the framework is another debate on the creation of a new body with some Parties being fiercely opposed to such a vision. Finally, the current work program contains some ideas which are generally accepted, while others will meet with stiff resistance, such as including a connection to Article 4.15 of the Paris Agreement. 


\section{CONCLUSIONS}

52. A positive conclusion can be reached at COP 25, and is very likely to happen. The issues outlined above, the options, and their consequences have been well-debated. While many require some technical sophistication and understanding of market functioning, the decisions are by and large political in nature. Political guidance on issues of "principle" will unlock operational issues. Identifying and expressing these issues of "principle" will be the real test leading up to, and in Madrid. This needs to be addressed early, and cannot be left to the end of COP 25.

53. However, as also mentioned in this paper, making pure political compromises that disregard market realities may spell success in Madrid, but will also mean significant time and work to address their consequences. The work needed to reform the CDM after Marrakech should provide useful lessons.

54. Above all, the analysis in this paper points to pragmatic solutions. Taking ideologically pure positions and making a litmus test out of them is unlikely to lead to a happy ending. The Paris Agreement is a promise that all Parties will work and evolve together. Some provisions that lead to imperfections with very minor impact on the ultimate goal may therefore be worth considering as a compromise and temporary outcome that will scrub itself out in time. Nothing is forever, and the 2023 stocktaking is just around the corner.

55. What will be worth watching over the next few days leading up to Madrid is who will champion the agreement on the Article 6 rule book. Keeping to a club of Parties that share the same views will not be enough. While some of the concerns raised at SBSTA 49 and 50 are more genuine than others, reaching out to those with legitimate issues will be the real test. 


\title{
APPENDIX 1
}

\author{
DRAFT TEXT \\ on \\ SBSTA 50 agenda item 11(a) \\ Matters relating to Article 6 of the Paris Agreement: \\ Guidance on cooperative approaches referred to in Article 6, paragraph 2, \\ of the Paris Agreement \\ Version 2 of 26 June 16:45:00 hrs (edited)
}

\section{Draft CMA decision on guidance on cooperative approaches referred to in Article 6, paragraph 2, of the Paris Agreement}

[The Conference of the Parties serving as the meeting of the Parties to the Paris Agreement,

Recalling Article 2 of the Paris Agreement and decision 1/CP.21.

Also recalling Article 6 of the Paris Agreement and decision 1/CP.21, paragraph 36.

1. [Adopts the [initial] guidance on cooperative approaches referred to in Article ${ }^{1} 6$, paragraph 2 as contained in the annex; ]

2. [Decides that this guidance supercedes decision 18/CMA.1, paragraph 77(d);

3. [Requests the SBSTA to develop common tabular formats for the electronic reporting of information under this guidance; ]

4. [Requests the SBSTA to undertake the following work, on the basis of the annex, to develop a draft decision on the [remaining] guidance on cooperative approaches referred to in Article 6, paragraph 2, for consideration and adoption by the CMA at its third session, as an integral part of the guidance:

(a) Further elaboration, if required, of the special circumstances of the least developed countries and small island developing States;

(b) Elaboration of how corresponding adjustments may be applied [in metrics other than $\mathrm{CO}_{2}$ equivalent determined by participating Parties][to all metrics of participating Parties' nationally determined contributions (NDCs)];

(c) Consideration of methods applied between participating Parties to ensure corresponding adjustments are consistent and representative of NDC implementation and achievement with regard to multi-year and single-year NDCs, as referred to in the annex, [section V.B (Multi-year and single-year nationally determined contributions)] [section V (Corresponding adjustments)];

(d) Consideration of how the application of corresponding adjustments to the total quantity of emission reductions achieved may be incorporated into the approach of applying corresponding adjustments to emissions and removals covered by the NDC, as referred to in the annex, section V (Corresponding adjustments);

(e) Further elaboration of the information to be reported by participating Parties, as referred to in the annex, section VII (Reporting), including the agreed tabular format referred to in annex, section VII (Reporting) and the agreed electronic format referred to in section IX (Recording of corresponding adjustments);

(f) Elaboration of guidance for the Article 6 technical expert review;

(g) Elaboration of the requirements relating to the recording of information in the Article 6 database;

(h) Elaboration of the requirements relating to the implementation of an international registry;

(i) [Elaboration of the requirements relating to the international transaction log; ]

(j) [Elaboration of the requirements relating to the implementation of the centralized accounting and recording platform;]

1 "Article" refers to an Article of the Paris Agreement, unless otherwise specified. 
(k) [Implementation of the share of proceeds referred to in section XII below including considering needs basis and distributing excess funds to adaptation;]

Option A $\{$ Section XI of the Annex text and maintaining safeguards and limits in the cover decision as a work programme $\}]$

(1) [Safeguards and limits, including consideration of the following:

(i) Transfer limits;

(ii) Minimum holding requirements;

(iii) Use of ITMOs towards achievement of its NDC being supplemental to domestic action such that domestic action constitutes a significant element of the effort made by each Party towards achievement of its NDC;

(iv) Maximum limits on the use of ITMOs towards an NDC;

(v) Requirements relating to carry-over of ITMOs from one NDC period to the next;

(vi) [Limits relating to the use by a Party of ITMOs from emissions and removals not covered by the sectors and gases included in its NDC towards achievement of its own NDC, including the use of cancellation and locked credits; ]

(vii) [Creation and first transfer of ITMOs in a manner that avoids significant fluctuations in the prices and quantities available in the international market for ITMOs; ]

(viii) [Creation and first transfer of ITMOs from sectors that have a[ high degree of uncertainty][Requirements to have a system to [address][ensure] permanence, including addressing reversals;]

(ix) [Requirements relating to avoiding unilateral measures and discriminatory practices in cooperative approaches;

(x) [Use of Article 6 shall aim to deliver an overall mitigation in global emissions and enhance mitigation and adaptation ambition;]

(xi) [Use of Article 6 should not lead to other environmental and social impacts, and should respect human rights in its application.]

Option B $\{$ See section XI in the Annex, where Option B sets out the safeguards and limits in the Annex\}

\section{Option C}

(xii) [Use of Article 6 should not lead to an increase in emissions in and between NDC implementation periods.]]

5. [Requests the SBSTA to develop a work programme to assist Parties][Requests the secretariat to assist Parties, in particular developing country Parties, through a work programme] to incorporate sectors and/or gases into their NDC in order to enable participation in cooperative approaches referred to in Article 6 paragraph 2;]

6. [Also requests the Subsidiary Body for Scientific and Technological Advice to undertake the first review of and update, as appropriate, the guidance no later than the end of 2024, on the basis of recommendations from the SBSTA and the SBI;]

7. [Decides that Parties voluntarily participating in cooperative approaches referred to Article 6, paragraph 2, shall apply decision 4/CMA.1, to their first NDCs; ]

8. [Affirms that all Parties participating in cooperative approaches shall apply the guidance contained in the Annex, throughout the entire period for NDC implementation, from the start of their participation;]

9. [Also affirms that, pursuant to the modalities, procedures and guidelines for the enhanced transparency framework under decision 18/CMA.1, for Parties participating in cooperative approaches referred to in Article 6, paragraph 2, the technical expert review referred to in decision 18/CMA.1, shall refer to this guidance when reviewing that participation, including when reviewing biennial transparency reports;] 
10. [Requests the secretariat to collaborate with the forum on the impact of the implementation of response measures (referred to in paragraph 33 of decision 1/CP.21) to consider ways to address any negative social and economic impacts, especially on developing country Parties, resulting from Article 6, paragraph 4, activities by, inter alia regularly sharing relevant information with the forum on the impact of the implementation of response measures in order to support the activities above; ]

11. [Requests the secretariat to undertake preparatory technical work, including technical papers and financial and technical feasibility studies, as required, for consideration by the SBSTA at its fifty-second session (June 2020), on the elements referred to in paragraph 2 above; ]

12. [Takes note of the estimated budgetary implications of the activities to be undertaken by the secretariat referred to in this decision and requests that the actions called for in this decision be undertaken subject to the availability of financial resources.] 


\section{Annex}

\section{Guidance on cooperative approaches referred to in Article 6, paragraph 2, of the Paris Agreement}

\section{Definitions}

1. The following definitions apply to this guidance:

(a) "Internationally transferred mitigation outcomes ("ITMOs")" are [to]:

(i) $\quad[\mathrm{Be}][\mathrm{real}][\mathrm{verified]} \mathrm{[additional]} \mathrm{[and} \mathrm{permanent]} \mathrm{[and} \mathrm{has} \mathrm{a} \mathrm{system} \mathrm{to} \mathrm{[ensure][address]}$ permanence, including addressing reversals] \{based on text from 8 December SBSTA text, paragraph $28(h)($ iv);

(ii) $[[\mathrm{Be}]$ in the form of anthropogenic emissions by sources [and removals [by sinks]] [avoidance]] \{text from 8 December SBSTA text, start of paragraph 1(a)(ii)\}, including mitigation co-benefits resulting from adaptation actions and/or economic diversification plans, or the means to achieve them;

(iii) $\left[[\mathrm{Be}]\right.$ measured in metric tonnes of carbon dioxide equivalent $\left(\mathrm{tCO}_{2} \mathrm{eq}\right)$ in accordance with the methodologies and common metrics assessed by the IPCC and adopted by the CMA [and/or in other metrics determined by participating Parties [consistent with the (nationally determined contributions (NDCs) of the participating Parties];]

(iv) $[\mathrm{Be}][\mathrm{a}$ unit held in a registry] [with a unique serial number][or][represent a net flow between participating Parties [or] [an amount in $\mathrm{tCO}_{2}$ eq representing mitigation outcomes;]

(v) $[[\mathrm{Be}]$ from a cooperative approach between participating Parties that involve the authorized transfer of mitigation outcomes that are intended for use towards an NDC; ]

(vi) $\left[[\mathrm{Be}]\right.$ amounts denominated in $\mathrm{tCO}_{2}$ eq authorised for use towards NDCs, or authorised for use towards other international mitigation purposes, and representing transfers from a cooperative approach or the mechanism; ]

(vii) [[Include] [emission reductions][, removals] [and avoidance]] under the mechanism established by Article ${ }^{2}$ 6, paragraph 4, [when internationally transferred [and used towards an NDC][for use towards and NDC or for other international mitigation purposes]];

(b) ["Overall mitigation in global emissions" is achieved when, through the operation of Article 6, a fixed percentage of ITMOs, duly reported, are not used by any Party or entity to implement or achieve its nationally determined contribution (NDC) or used for any other compliance purposes outside Article 6; ] text from 8 December SBSTA text, paragraph 1(c)\}

(c) "Transfer" [means an international transfer of one or more mitigation outcomes that has been authorized by the participating Party, which may be the only transfer of those mitigation outcomes and may include the transfer of a claim to the mitigation outcome] [means an international transfer of one or more mitigation outcomes, that has been authorized by the transferring Party, [and includes transfer of a claim;]] \{text from 8 December SBSTA text, paragraph 1(d)\} "First transfer" means the first such transfer of one or more mitigation outcomes;

(d) "Vintage" means the year in which the mitigation took place.

\section{Governance}

2. The CMA may adopt further guidance pursuant to Article 6, paragraph 2.

2 "Article" refers to an Article of the Paris Agreement, unless otherwise specified. 
3. Each Party participating in a cooperative approach that involves the use of ITMOs towards NDCs, as referred to in Article 6, paragraph 2, ("participating Party") shall ensure that its participation in the cooperative approach and its transfers and use of ITMOs towards NDCs is consistent with this guidance and further guidance as referred to in paragraph 2 above.

4. An Article 6 technical expert review shall review the application of this guidance by participating Parties and forward its recommendations to the technical expert review process under decision 18/CMA. 1 . The review shall be conducted on the basis of information provided by each participating Party pursuant to section VII below (Reporting) and section IX below (Recording of corresponding adjustments), and pursuant to any further guidance to be adopted by the CMA.

5. The secretariat, pursuant to Article 17, shall carry out the activities relating to it set out in this guidance.

6. The secretariat shall [periodically][at least [annually]] prepare a compilation and synthesis of the results of the Article 6 technical expert review, including identification of recurring themes and lessons learned, [and recommendations for improvements to the guidance] for consideration by the CMA.

\section{Participation responsibilities}

7. Each participating Party shall ensure that:
(a) It is a Party to the Paris Agreement;
(b) It has prepared, communicated and is maintaining an NDC in accordance with Article 4, paragraphs 2 and 6 , and decision 4/CMA.1;
(c) It has authorized the use of ITMOs towards NDCs[, or for other international mitigation purposes] pursuant to Article 6, paragraph 3, and has made that authorization public;
(d) It ensures tracking of ITMOs pursuant to section IV (Tracking internationally transferred mitigation outcomes);
(e) It has provided the most recently required national inventory report in accordance with decision 18/CMA.1;
(f) [It has a national registry connected to the international transaction log pursuant to section $\mathrm{X}$ (Infrastructure) below.]

8. [Parties are encouraged to deliver an overall mitigation in global emissions in the context of Article 6, paragraph 2, through a voluntary cancellation or setting aside of ITMOs that are not used for any transfer or purpose, including use by any Party towards its NDC.] \{Parties may wish to refer to Section XIII\}

\section{Tracking internationally transferred mitigation outcomes}

9. [Each participating Party][The Article 6 database]shall ensure the tracking and identification of ITMOs through a registry pursuant to section $\mathrm{X}$ below (Infrastructure), including \{Some Parties identified a need for refinement of the tracking requirements below $\}$ :
(a) [Creation of ITMOs; ]
(b) First transfer of ITMOs;
(c) Transfer of ITMOs;
(d) Acquisition of ITMOs;
(e) [Holding of ITMOs; ]
(f) [Cancellation of ITMOs;
(g) [Use of ITMOs;
(h) [Voluntary cancellation of ITMOs; 
(i) [Mandatory cancelling ITMOs for overall mitigation in global emissions; \{based on text from 8 December SBSTA text, paragraph 11(h)\}

(j) [Voluntary cancellation for an overall mitigation in global emissions; ]

(k) [Transfer of ITMOs for the share of proceeds for adaptation.]

V. Corresponding adjustments SSome Parties identified a need for refinement in Section $V$, inter alia: in sequencing of timing of recording of transfers and acquisitions, the availability of inventory data for applying corresponding adjustments, tracking structures for ITMOs\}

\section{A. Basis for corresponding adjustments}

\section{Option A}

10. [For ITMOs measured in a metric determined by participating Parties, each participating Party shall consistently apply its corresponding adjustments by effecting an addition or subtraction from a starting point of a zero balance, with a resulting balance that reflects net transfers and acquisitions and is applied to the NDC in accordance with guidance under Article 4, paragraph 13, Article 6, paragraph 2, and Article 13, paragraph 13. The corresponding adjustment shall be effected through an addition for ITMOs transferred and a subtraction for ITMOs acquired.

11. For ITMOs measured in tonnes of $\mathrm{CO}_{2} \mathrm{e}$, each participating Party shall consistently apply its corresponding adjustments by effecting an addition or subtraction to the emissions and removals covered by its NDC, as derived from its national inventory report, and reported pursuant to paragraph VII.B.42(a), resulting in an adjusted balance. The corresponding adjustment shall be effected through [either]:

(a) [An addition of the quantity of ITMOs first transferred and a subtraction of the quantity of ITMOs used;]

(b) [An addition of the quantity of ITMOs transferred and a subtraction of the quantity of ITMOs acquired].]

\section{Option B}

12. [For ITMOs measured in a metric determined by participating Parties, each participating Party shall [consistently] apply its corresponding adjustments by effecting an addition or subtraction from a starting point of a zero balance, with a resulting balance that reflects net transfers and acquisitions and is applied to the NDC in accordance with guidance under Article 4, paragraph 13, Article 6, paragraph 2, and Article 13, paragraph 13. The corresponding adjustment shall be effected through an addition for ITMOs transferred and a subtraction for ITMOs acquired.

13. For ITMOs measured in tonnes of $\mathrm{CO}_{2} \mathrm{e}$, each participating Party shall consistently apply its corresponding adjustments by effecting an addition or subtraction to the emissions and removals covered by its NDC, as derived from its national inventory report, and reported pursuant to paragraph VII.B.42(a), resulting in an adjusted balance. The corresponding adjustment shall be effected through [either]:

(a) [An addition of the quantity of ITMOs first transferred and a subtraction of the quantity of ITMOs used;]

(b) [An addition of the quantity of ITMOs transferred and a subtraction of the quantity of ITMOs acquired].]

Option C \{text from 8 December SBSTA text, paragraph 12(a)\}

14. [A budget basis, by effecting an addition or subtraction to its quantification of the greenhouse gas emissions level corresponding to its NDC. The corresponding adjustment shall be effected through a subtraction for ITMOs transferred and an addition for ITMOs acquired.]

Option D $\{$ text from 8 December SBSTA text, paragraph 12(c)-(d)\}

15. [A buffer-registry basis: 
(a) For ITMOs measured in any metric determined by participating Parties, by effecting an addition or subtraction from a starting point of a zero balance, with a resulting balance that reflects net transfers and acquisitions and is applied to the NDC in accordance with guidance under Article 4, paragraph 13 and Article 13.7(b) purposes;

(b) For ITMOs measured in tonnes of $\mathrm{CO}_{2} \mathrm{e}$, the emissions basis may be applied;

16. The corresponding adjustment shall be effected through an addition for ITMOs transferred and a subtraction for ITMOs acquired.]

\section{Option E}

17. [For ITMOs measured in a metric consistent with the NDCs of the participating Parties, each participating Party shall have the same NDC metric and shall consistently apply its corresponding adjustments by effecting an addition or subtraction from a starting point of a zero balance, with a resulting balance that reflects net transfers and acquisitions and is applied to the NDC in accordance with guidance under Article 4, paragraph 13, Article 6, paragraph 2, and Article 13, paragraph 13. The corresponding adjustment shall be effected through an addition for ITMOs transferred and a subtraction for ITMOs acquired, applied to the NDC.]

\section{B. Multi-year and single-year nationally determined contributions}

\section{Option A}

18. [Each participating Party that has a multi-year NDC shall apply one of the following methods consistently throughout its period for NDC implementation:

(a) Calculating a multi-year emissions trajectory for the period for NDC implementation that is consistent with the NDC, and applying a corresponding adjustment for each year covered by this emissions trajectory;

(b) Applying a corresponding adjustment for each year in the period for NDC implementation;

(c) Applying a corresponding adjustment at the end of the NDC period for the total amount of ITMOs first transferred and used, or transferred and acquired over the period of the NDC implementation.

19. Each participating Party that has a single-year NDC shall apply, in order to make the corresponding adjustments in the NDC year consistent with and representative of NDC implementation and achievement, one of the following methods consistently throughout the period for NDC implementation:

(a) The method referred to in paragraph 18(a) above;

(b) The method referred to in paragraph 18(b) above;

(c) The method referred to in paragraph 18(c) above, where both participating Parties apply this method for the cooperative approach;

(d) Calculating the average annual amount of ITMOs first transferred and used, or transferred and acquired over the period of the NDC implementation, and applying a corresponding adjustment equal to this average amount for the NDC year;

(e) The Party may only first transfer or transfer consistent with this section, ITMOs that are of the same vintage as the Party's single year NDC and/or only acquire or use ITMOs that are of the same vintage as the Party's single-year NDC.

20. Participating Parties shall apply the same method consistently throughout the period for NDC implementation.

21. Each participating Party shall report its corresponding adjustments pursuant to section VII below (Reporting) and record the corresponding adjustments in the Article 6 database pursuant to section IX below (Recording of corresponding adjustments).] 


\section{Option B}

22. Each participating Party that has a multi-year NDC shall apply one of the following methods consistently throughout its period for NDC implementation:

(a) Calculating a multi-year emissions trajectory for the period for NDC implementation that is consistent with the NDC, and applying a corresponding adjustment for each year covered by this emissions trajectory [for the total amount of ITMOs first transferred and used, or transferred and acquired over the NDC implementation period];

(b) [Applying a corresponding adjustment for each year in the period for NDC implementation;]

(c) Applying a corresponding adjustment at the end of the NDC period for the total amount of ITMOs first transferred and used, or transferred and acquired over the period of the NDC implementation.

23. Each participating Party that has a single-year NDC shall apply, in order to make the corresponding adjustments in the NDC year consistent with and representative of NDC implementation and achievement, one of the following methods consistently throughout the period for NDC implementation:

(a) [The method referred to in paragraph 22(a) above; ] [Calculating an indicative multi-year emissions trajectory for the period for NDC implementation that is consistent with the NDC, and] [a][A]pplying a corresponding adjustment for the [total] amount of ITMOs first transferred and used, or transferred and acquired, for each year in the NDC implementation period;]

(b) [The method referred to in paragraph 22(b) above; ]

(c) [The method referred to in paragraph 22(c) above, where both participating Parties apply this method for the cooperative approach;]

(d) [Calculating the average annual amount of ITMOs first transferred and used, or transferred and acquired over the period of the NDC implementation and applying a corresponding adjustment equal to this average amount for the NDC year;]

(e) [The Party may only first transfer or transfer consistent with this section, ITMOs that are of the same vintage as the Party's single year NDC and/or only acquire or use ITMOs that are of the same vintage as the Party's single-year NDC.]

24. [Participating Parties shall apply the same method consistently throughout the period for NDC implementation.]

25. Each participating Party shall report its corresponding adjustments pursuant to section VII below (Reporting) and record the corresponding adjustments in the Article 6 database pursuant to section IX below (Recording of corresponding adjustments).

\section{Option C}

26. [In its initial report pursuant to section VII.A (initial report), [in order to make corresponding adjustments in the NDC year consistent with and representative of NDC implementation and achievement,] a participating Party may identify its method for corresponding adjustments from [the methods in this section] to be applied consistently throughout the NDC implementation period. If a Party does not identify the method, the following default method applies:

(a) For a multi-year NDC, [calculating a multi-year emissions trajectory for the period for NDC implementation that is consistent with the NDC, and] applying a corresponding adjustment for the total amount of ITMOs first transferred and used, or transferred and acquired, for each year in the NDC implementation period;

(b) For a single year NDC, calculating the average annual amount of ITMOs first transferred and used, or transferred and acquired over the period of the NDC implementation period and applying a corresponding adjustment equal to this average amount for the NDC year.]

\section{Option D}

27. [Each participating Party shall apply the following principles when selecting a method for corresponding adjustment [from the methods in this section]: that corresponding adjustments shall be consistent with and representative of the participating Party's NDC implementation and achievement; that the use of Article 6 
does not lead to an increase in emissions in or between the Participating Party's NDC implementation periods; that the Party ensures transparency, accuracy, completeness, consistency and comparability.]

Option E \{based on the 8 December SBSTA text, paragraph 24$\}$

28. [All Parties apply the following method consistently throughout its period for NDC implementation:

(a) Quantification of allowable emissions through calculating how many tonnes of CO2e could be emitted while achieving its NDC;

(b) Multiplied by the number of years in the NDC, converted into a number of units, each corresponding to one tonne of $\mathrm{CO} 2 \mathrm{e}$;

(c) Where that number exceeds the average annual emissions for the years preceding the NDC, as per the last three national inventories, the difference, multiplied by the number of years in the NDC to be reserved for domestic use only;

(d) The resulting figure represents the quantified NDC.]

\section{VI. [Application of guidance}

\section{A. Internationally transferred mitigation outcomes from sectors and greenhouse gases covered by nationally determined contributions}

29. A Party that transfers ITMOs for emission reductions and removals from sectors and greenhouse gases covered by the NDC of the Party shall apply corresponding adjustments pursuant to section V above (Corresponding adjustments).

Option A

30. A Party that transfers ITMOs from emission reductions and removals from sectors and greenhouse gases that are not covered by the NDC of the Party [shall apply corresponding adjustments pursuant to section V above (Corresponding adjustments)] [is not required to apply corresponding adjustments pursuant to section V above (Corresponding adjustments) [until 2031]].

Option B

31. [A Party that transfers ITMOs from emission reductions and removals from sectors and greenhouse gases that are not covered by the NDC of the Party shall apply corresponding adjustments pursuant to section V above (Corresponding adjustments). A host Party is not required to apply corresponding adjustments for first transfers of units from the mechanism established in Article 6, paragraph 4, where they are achieved from activities not covered by the NDC of the host Party.]

$\{$ end of option $B$ \}

32. [The crediting period for the activities not covered by the NDC of the host Party may be shorter than the crediting period for the activities covered by the NDC.]

Option C

33. [Parties may only transfer ITMOs from cooperative approaches and the mechanism, where those ITMOs resulted from emission reductions and removals from sectors and GHGs covered by the scope of Parties's NDC.]

Option D $\{$ no text required $\}$ 


\section{B. Purposes other than towards nationally determined contributions}

Option A

34. [Pursuant to guidance relating to Article 4, paragraph 13,] where a Party expressly authorizes the use of mitigation outcomes, for a purpose other than towards an NDC, this guidance shall apply to such mitigation outcomes, whether or not they have been internationally transferred.

Option B

35. ITMOs cannot be used for purposes other than towards NDCs.

Option C

36. [Parties shall apply adjustments for the use of mitigation outcomes for an international mitigation purpose other than towards an NDC, whether or not they have been internationally transferred but a host Party is not required to apply adjustments for first transfers of units from the mechanism established in Article 6, paragraph 4, where the units are achieved from activities not covered by the NDC of the host Party.]

\section{Special circumstances of the least developed countries and small island developing States}

37. In relation to the least developed countries and small island developing States, pursuant to Article 4, paragraph 6 , their special circumstances shall be recognized where the guidance relates to NDCs and other aspects of their special circumstances may be recognized in further decisions of the CMA relating to that guidance.]

\section{Reporting}

\section{A. Initial report}

38. For each NDC communicated or updated, each participating Party shall, [at the outset of the NDC implementation period][prior to or at the time of first transfer or acquisition of ITMOs[, including units from the mechanism established in Article 6, paragraph 4]], submit an initial report containing comprehensive information to:

(a) Demonstrate that it fulfils the participation responsibilities referred to in section III above (Participation responsibilities);

(b) Communicate its period for NDC implementation, including the start and end date;

(c) [Communicate its basis for corresponding adjustments pursuant to section V.A above (Basis for corresponding adjustments) [and its method pursuant to section V.B above (Multi-year and singleyear nationally determined contributions) to be applied consistently throughout its period for NDC implementation.] [and shall communicate its method pursuant to section V.B above (Multi-year and single-year nationally determined contributions) to be applied consistently throughout its period for NDC implementation or apply the default method in section V.B.26 above]][ Communicate its basis for corresponding adjustments pursuant to section V.B.28 above]. \{this relates to Option $E$ in that section\}

(d) [Quantify its NDC in tonnes of $\mathrm{CO}_{2} \mathrm{e}$, including the sectors, sources, greenhouse gases and time periods covered by its NDC, the reference level of emissions and removals for the relevant year or period, and the target level for its NDC; where this is not possible, provide the methodology for the quantification of its NDC in tonnes of $\mathrm{CO}_{2} \mathrm{e}$.]

(e) [Quantify its NDC, or that portion of its NDC, in a metric determined by each participating Party applying corresponding adjustments in metrics other than greenhouse gases pursuant to section $\mathrm{V}$ above (Corresponding adjustments)]. 
(f) The initial report shall also include the information [[in relation to each cooperative approach] [that participating Parties intend to participate in] referred to in paragraphs B.39[, [B.40], B.41 [and B.42] below, as applicable. \{Some Parties identified a need for refinement through incorporating elements from regular reporting\}

B. Regular information \{Some Parties identified a need for refinement to avoid duplication of information with other reporting obligations $\}$

39. Each participating Party shall submit, in its biennial transparency report pursuant to decision 18/CMA.1, the following information in relation to its participation:

(a) How it fulfils its participation responsibilities referred to in section III (Participation responsibilities);

(b) Its institutional arrangements for authorization;

(c) Authorization of the use of ITMOs pursuant to Article 6, paragraph 3;

(d) How it has ensured that the ITMOs used towards achievement of its NDC will not be further transferred, acquired, cancelled or used;

40. Each participating Party shall also submit[, as part of its biennial transparency reports pursuant to decision 18/CMA.1] the following [qualitative] information in relation to how the cooperative approaches in which it participates:

(a) Support(s) the mitigation of greenhouse gas emissions and the implementation of its NDC;

(b) Ensure environmental integrity, such that there is no increase in global emissions, through robust, transparent governance and the quality of mitigation outcomes, including through stringent reference levels, baselines set in a conservative way and below 'business-as-usual' emission projections (including by taking into account all existing policies and addressing potential leakage) and ensuring the compensation of any material reversals;

(c) Where a mitigation outcome is measured and transferred in $\mathrm{tCO}_{2} \mathrm{eq}$, provide for the measurement of mitigation outcomes in accordance with the methodologies and common metrics assessed by the IPCC and adopted by the CMA;

(d) [Where a mitigation outcome is measured and transferred in a metric other than $\mathrm{CO}_{2}$ eq determined by the participating Parties, provide for [consistency of the metric with the NDCs of the participating Parties;]]

(e) [Provide for, as applicable, the measurement of mitigation co-benefits resulting from adaptation actions and/or economic diversification plans;]

(f) Apply safeguards pursuant to section XI above (Safeguards and limits);

(g) [Do not result in environmental harm; ]

(h) Address any risks of conflict with other environment-related aspects;

(i) [Are consistent with sustainable development in the host Party, noting national prerogatives] [Are consistent with the [Sustainable Development Goals] and the sustainable development objectives of the host Party, noting national prerogatives] text from 8 December SBSTA text, paragraph 28(i)(iv)\};

(j) [Avoid unilateral measures and discriminatory practices in cooperative approaches; ]

(k) [Are consistent with the Party's respective obligations on human rights;

(l) [Avoid causing negative social or economic impacts on any Party.]

41. Each participating Party should also submit information on its long-term low emission development strategy pursuant to Article 4, paragraph 19, if available.

42. Each participating Party shall submit the following quantitative information pursuant to section IX above (Recording of corresponding adjustments)[annually[ from 202X]] [annually after it submits its initial 
report] [, as part of its biennial transparency reports pursuant to decision 18/CMA.1], in an [agreed tabular format] \{Some Parties identified a need for refinement of the timing, format and destination of the information in this section $\}$ :

(a) [Annual and cumulative emissions and removals in relation to the sectors, sources, greenhouse gases and time periods covered by its NDC;]

(b) Annual and cumulative ITMOs first transferred, transferred, acquired, held, cancelled and/or used by participating Parties, distinguishing ITMOs from sectors, sources and greenhouse gases that are covered and not covered by the NDC of the Party and including information on the other participating Party transferring, acquiring and/or using the ITMOs, the originating cooperative approach, sector, vintage[ and metric used];

(c) Annual and cumulative[, including indicative] corresponding adjustments applied pursuant to section V (Corresponding adjustments), including information on the other participating Parties[ and the metric used];

(d) [Annual and cumulative ITMOs authorized for use for a purpose other than towards NDCs, including information, as applicable, on the transferrer, acquirer and/or user of the ITMOs; ]

(e) Adjusted [indicative emissions] balances, as applicable, after applying corresponding adjustments for the annual period and/or the full NDC implementation period pursuant to section $\mathrm{V}$ above (Corresponding adjustments);

(f) [Annual and cumulative ITMOs transferred pursuant to section XII below (Share of proceeds for adaptation);]

(g) [Annual and cumulative ITMOs cancelled in accordance with section XIII below (Overall mitigation in global emissions); \{text from 8 December SBSTA text, paragraph 30(e)\}]

43. Participating Parties shall publish and keep up-to-date, through the [UNFCCC website][Article 6 database], all publicly available information on cooperative approaches in which they participate.

\section{Review}

44. The Article 6 technical expert review pursuant to section II (Governance) shall review the information contained in the initial report of the Party pursuant to section VII.A (Initial report) for consistency with this guidance.

45. The Article 6 technical expert review shall also review information reported pursuant to section VII.B (Regular information) [and][,] information recorded pursuant to section IX below (Recording of corresponding adjustments) [and information in the centralized recording and accounting platform] for consistency with this guidance. \{Some Parties identified a need for refinement and further elaboration of the process of the Article 6 technical expert review $\}$

46. The Article 6 technical expert review may make recommendations to the participating Party on how to improve its consistency with this guidance, including how to address inconsistencies in quantified information. The Article 6 technical expert review shall forward its reports for consideration by the technical expert review process under decision 18/CMA.1.

47. [The Article 6 technical expert review may forward its report to the committee referred to in Article 15, paragraph 2, if the review reveals a [systemic issue][significant inconsistencies].] [Following the review, the committee referred to in Article 15, paragraph 2, shall consider the review in accordance with its modalities and procedures. \{second sentence is text from 8 December SBSTA text, paragraph 35)\}]

\section{Recording [of corresponding adjustments]}

48. The secretariat shall, upon submission by participating Parties, record information contained in initial reports pursuant to section VII above (Reporting), in the Article 6 database pursuant to section X (Infrastructure). 


\section{Option A}

49. [Each participating Party shall, on an annual basis and in the agreed electronic format, submit the quantitative information pursuant to section VII above (Reporting), including information on corresponding adjustments pursuant to section $\mathrm{V}$ above (Corresponding adjustments) to the secretariat for recording in the Article 6 database.]

\section{Option B}

50. [Each participating Party shall, on an annual basis and in the agreed electronic format, submit the information on annual and cumulative ITMOs pursuant to VII.B.42(b) above to the secretariat for recording in the Article 6 database.]

\{end of Option B\}

51. The secretariat shall compile the information submitted by participating Parties in the Article 6 database and it shall:

(a) Perform a consistency check including on the information on the corresponding adjustments submitted by participating Parties;

(b) Notify the participating Parties of any inconsistencies;

(c) [Make available to the Article 6 technical expert review the compiled information relevant to a participating Party's cooperative approach(es).]

52. Any amendments to the information recorded in the Article 6 database, including as a result of recommendations from the Article 6 technical expert review, may also be submitted by the participating Party concerned for recording in the Article 6 database.

53. [At the end of the NDC implementation period, each participating Party applying the budget basis shall retire the number of units equal to the emissions and removals covered by its NDC. Such retirement shall be made in the international registry pursuant to section XII (Infrastructure).] \{text from $8^{\text {th }}$ December SBSTA text, paragraph 39$\}$

\section{Infrastructure}

\section{Option A}

54. Each participating Party shall have, or have access to, a registry for tracking ITMO information. Each registry shall be able to perform the functions referred to in section IV above (Tracking internationally transferred mitigation outcomes) and shall have the necessary accounts.

55. The secretariat shall implement an international registry [in combination with the mechanism registry for the Article 6, paragraph 4 registry], for participating Parties that do not have such a registry or access to such a registry [as part of a centralized accounting and recording platform that also encompasses the Article 6 database. This publicly accessible platform shall provide oversight over tracking and identification under section IV above and support reviews under section VIII above].

56. The secretariat shall implement an Article 6 database[, as part of the centralized accounting and recording platform] to record and compile information pursuant to section IX (Recording of corresponding adjustments). Non-confidential information recorded in the Article 6 database shall be publicly accessible. The Article 6 database shall perform the following functions:

(a) [Tracking ITMOs, first transferred, transferred, acquired, held, cancelled and/or used by participating Parties[ through unique identifiers that include the identity of the underlying source Party, vintage or underlying reduction, activity type and sector];]

(b) [Maintain public information on transfers and acquisitions of ITMOs; ]

(c) [Maintain links to the publicly available information submitted by participating Parties on the cooperative approaches in which they participate, pursuant to VII.B.43 above;]

(d) [Checking the consistency of ITMOs reported by participating Parties with requirements for corresponding adjustment and avoiding double counting;] 
(e) [Identifying inconsistencies to the participating Parties; ]

(f) [Checking the authorization by participating Parties; ]

(g) [Prefilling common tabular formats; $\{$ text from 8 December SBSTA text, paragraph $46(a)-(d)\}$

(h) [Provide an annual report including information on all ITMOs to [X]].

\section{Option B}

57. [The secretariat shall establish and maintain an international transaction log capable of recording the information set out in this section and any further decisions of the CMA relating to this guidance.] \{text from 8 December SBSTA text, paragraph 49$\}$

58. [Each participating Party shall ensure that its registry is capable of connection to the international transaction log.] \{text from 8 December SBSTA text, paragraph 50\}

\section{Safeguards and limits}

\section{Option A}

59. Each participating Party shall apply, [as appropriate][as applicable], any safeguards and limits adopted by the CMA in relation to cooperative approaches referred to in Article 6, paragraph 2 \{See cover decision paragraph 2(j) for work programme on safeguards and limits $\}$.

Option B \{return of safeguards and limits under a work programme from the cover decision to the Annex\}

60. [Each participating Party shall apply[, as applicable,] the following safeguards and limits:
(a) [Transfer limits; $]$
(b) [Minimum holding requirements;

(c) [Use of ITMOs towards achievement of its NDC being supplemental to domestic action such that domestic action constitutes a significant element of the effort made by each Party towards achievement of its NDC; ]

(d) [Maximum limits on the use of ITMOs towards an NDC;

(e) [Requirements relating to carry over of ITMOs from one NDC period to the next; ]

(f) [Limits relating to the use by a Party of ITMOs from emissions and removals not covered by the sectors and gases included in its NDC towards achievement of its own NDC, including the use of cancellation and locked credits];

(g) [Creation and first transfer of ITMOs in a manner that avoids significant fluctuations in the prices and quantities available in the international market for ITMOs];

(h) [Creation and first transfer of ITMOs from sectors that have a high degree of uncertainty] [system to [address][ensure] permanence, including addressing reversals]];

(i) [Requirements relating to avoiding unilateral measures and discriminatory practices in cooperative approaches];

(j) [Use of Article 6 should not lead to an increase in emissions in and between NDC implementation periods];

(k) [Use of Article 6 shall aim to deliver an overall mitigation in global emissions and enhance mitigation and adaptation ambition;]

(1) [Use of Article 6 should not lead to other environmental and social impacts, and should respect human rights in its application.]

Option C

61. [Each participating Party shall ensure that use of Article 6 should not lead to an increase in emissions in and between NDC implementation periods; ] 


\section{Share of proceeds for adaptation}

Option A \{text from 8 December SBSTA text, paragraphs 54-57\}

62. Cooperative approaches [shall][should] deliver a share of proceeds to be used to assist developing country Parties that are particularly vulnerable to the adverse effects of climate change to meet the costs of adaptation.

63. The share of proceeds [shall][should] be collected in respect of:

Option A1

(a) cooperative approaches that are baseline and crediting approaches that are similar to mitigation activities under the mechanism established by Article 6, paragraph 4 .

Option A2

(b) crediting approaches implemented by Parties.

Option A3

(c) all cooperative approaches.

\section{Option A4}

(d) all acquisition of ITMOs.

\{end of Option A4\}

64. The share of proceeds [shall][should] be set at and levied at:

\section{Option A1}

(a) $\quad X$ per cent $/ 5$ per cent/an increasing per cent/a diminishing per cent of the amount of ITMOs transferred/used towards achievement of an NDC.

\section{Option A2}

(b) $X$ percent at first transfer, increasing by $Y$ percent at each subsequent transfer.

\section{Option A3}

(c) Consistent with the share of proceeds pursuant to Article 6, paragraph 6, for the mechanism established by Article 6, paragraph 4 .

\{end of Option A3\}

65. The share of proceeds [shall][should] be:
(a) Collected by the creating/issuing Party at the first transfer of ITMOs and/or collected by a Party using ITMOs towards achievement of its NDC;
(b) Transferred by the creating/issuing Party to the Adaptation Fund;
(c) Collected by the acquiring Party at each ITMO transfer and transferred to the Adaptation Fund.

Option B \{text from 8 December SBSTA text, paragraphs 54-57\}

$\{$ no text required $\}$

\section{Option C}

66. Cooperative approaches [shall][should] deliver a share of proceeds to be used to assist developing country Parties that are particularly vulnerable to the adverse effects of climate change to meet the costs of adaptation.

67. The share of proceeds [shall][should] be collected in respect of [cooperative approaches that are baseline and crediting approaches that are similar to mitigation activities under the mechanism established by Article 6 paragraph 4] [crediting approaches implemented by Parties] [all cooperative approaches] [all acquisition of ITMOs]. 
68. The share of proceeds [shall][should] be set at and levied at [X per cent / 5 per cent / an increasing per cent / a diminishing per cent of the amount of ITMOs transferred / used towards achievement of an NDC] [X percent at first transfer, increasing by Y percent at each subsequent transfer] [consistent with the share of proceeds pursuant to Article 6, paragraph 6, for the mechanism established by Article 6, paragraph 4].

69. The share of proceeds [shall][should] be [collected by the creating/issuing Party at the first transfer of ITMOs and/or collected by a Party using ITMOs towards achievement of its NDC] [transferred by the creating/issuing Party to the Adaptation Fund] [collected by the acquiring Party at each ITMO transfer and transferred to the Adaptation Fund].

\section{Option D}

70. [Cooperative approaches [shall][should] deliver a share of proceeds to be used to assist developing country Parties that are particularly vulnerable to the adverse effects of climate change to meet the costs of adaptation, through a monetary levy of $[\mathrm{X}]$ per cent of the value of the ITMOs used towards an NDC.]

\{end of Option D\}

71. [Cooperative approaches [shall][should] deliver a share of proceeds to cover administrative expenses incurred by host Parties.]

\section{Overall mitigation in global emissions}

Option A $\{$ text from 8 December SBSTA text, paragraph 53$\}$

72. Overall mitigation in global emissions [shall][should] be implemented in the context of Article 6, paragraph 2, as follows:

Option A1

(a) On the basis of an automatic cancellation as follows:

(i) Overall mitigation in global emissions [shall][should] be achieved by ensuring some ITMOs are not used by either creating or acquiring Party towards achievement of its NDC;

(ii) At the time of issuance/first transfer of ITMOs, the registry [shall][should] transfer [X/10/20/30] per cent of ITMOs to the cancellation account for overall mitigation consistent with section XII (Infrastructure);

(iii) Transferring Party [shall][should] make a corresponding adjustment for the full amount of ITMOs created/issued/supplied for first transfer;

(iv) Acquiring/using Party [shall][should] make a corresponding adjustment for the amount of ITMOs acquired/used;

(v) The cancelled ITMOs [shall][should] not be used for any further transfer or purpose, including use by any Party towards achievement of its NDC or voluntary cancellation;

Option A2

(b) On the basis of a discounting by Parties as follows:

(i) Overall mitigation in global emissions [shall][should] be achieved by ensuring some ITMOs are not used by either creating or acquiring Party towards achievement of its NDC;

(ii) Prior to first transfer, creating Party [shall][should] make a corresponding adjustment for the full amount of ITMOs to be first transferred;

(iii) Acquiring/using Party [shall][should] make a corresponding adjustment for the full amount of ITMOs acquired/used, discounted by [X/10/20/30] percent;

(iv) The discounted volume of ITMOs [shall][should] be transferred to the cancellation account for the overall mitigation of global emissions by the acquiring/using Party;

(v) The discounted volume of ITMOs [shall][should] not be used for any further transfer or purpose, including use by any Party towards achievement of its NDC. 
\{end of text from 8 December SBSTA text, paragraph 53$\}$

Option B

(c) [In an manner consistent with the implementation of overall mitigation in global emissions in the mechanism established by Article 6, paragraph 4.]

Option C

$\{$ no text required $\}$

XIV. [Addressing negative social and economic impacts, Article 4, paragraph 15 \{text from 8 December SBSTA text, paragraph 58$\}$

73. The secretariat shall collaborate with the forum on the impact of the implementation of response measures (referred to in paragraph 33 of Decision 1/CP.21) to address negative social and economic impacts, especially those impacting developing countries, resulting from activities related to Article 6, paragraph 2, by the undertaking the following actions:

(a) Assessing and identifying the negative social and economic impacts resulting from activities related to Article 6, paragraph 2, including the cumulative impact of these activities;

(b) Developing, implementing and regularly updating measures to address the negative social and economic impacts resulting from activities related to Article 6, paragraph 2, including the cumulative impact of these activities;

(c) [Regular][Annual] sharing of information with the forum on the impact of the implementation of response measures (referred to in paragraph 33 of Decision 1/CP.21) to support the above activities.]] 


\title{
APPENDIX 2
}

\author{
DRAFT TEXT
}

on

SBSTA 50 agenda item 11(b)

Matters relating to Article 6 of the Paris Agreement:

Rules, modalities and procedures for the mechanism established by Article 6, paragraph 4, of the Paris Agreement

Version 2 of 26 June 15:30 hrs (edited)

\section{Draft CMA decision on the rules, modalities and procedures for the mechanism established by Article 6, paragraph 4, of the Paris Agreement}

[The Conference of the Parties serving as the meeting of the Parties to the Paris Agreement,

[Recalling the aims of the mechanism established by Article 6, paragraph 4, of the Paris Agreement (hereinafter referred to as the mechanism) referred to in paragraph $4(\mathrm{a}-\mathrm{d})$ of that Article, $\left.{ }^{1}\right]$

[Recognizing that the mechanism is to be operationalized in the context of the Paris Agreement, in particular its preamble and its Articles 2 and 3, Article 4, paragraphs 3, 4 and 15, Article 6, paragraphs 5 and 6, and Articles 13 and 15,]

1. [Establishes the body that will supervise the mechanism with its membership and [initial] rules of procedure as set out in the annex;]

2. [Designates the body referred to in paragraph 1 above as the supervisory body of the mechanism and names it the Supervisory Body; ]

3. [Welcomes the election of the first members of the Supervisory Body;

4. [Requests the secretariat to organize the meetings of the Supervisory Body;]

5. [Also requests the Supervisory Body to meet at least once during 2020 in order to develop recommendations on the following matters for consideration by the Subsidiary Body for Scientific and Technological Advice (SBSTA) at its fifty-second session (June 2020) and/or its fifty-third session (November 2020):

(a) Further elaboration of its rules of procedure;

(b) [Relevance of baseline and monitoring methodologies and accreditation standards under the clean development mechanism under Article 12 of the Kyoto Protocol to the mechanism;]

6. [Adopts the [initial] provisions of the rules, modalities and procedures for the mechanism, as contained in the annex;]

7. [Requests the SBSTA to undertake further work to develop the [remaining] provisions of the rules, modalities and procedures for the mechanism with regard to the following elements, for consideration and adoption by the Conference of the Parties serving as the meeting of the Parties to the Paris Agreement (CMA) at its third session (November 2020) as an integral part of the rules, modalities and procedures for the mechanism:

(a) Further provisions for the rules of procedure of the Supervisory Body that may be required in addition to those set out in section III.A. of the annex (Rules of procedure), [taking into account the recommendations from the Supervisory Body as referred to in paragraph 5(a) above];

(b) Further provisions on the special circumstances of the least developed countries and small island developing States that may be required in addition to those set out in section IV (Participation responsibilities) [and section VI.B (Methodologies)] of the annex, including, inter alia with regard to baseline setting and the additionality of activities under Article 6, paragraph 4 (hereinafter referred to as Article 6, paragraph 4 activities), hosted by such Parties;

${ }^{1}$ In the context of this decision, "Article" refers to an Article of the Paris Agreement, unless otherwise specified. 
(c) Further responsibilities of the Supervisory Body and the host Parties that may be required for the mechanism to operate with a more host Party led/decentralized model;

(d) Further provisions on the share of proceeds for administrative expenses in addition to those set out in sections VI.E (Registration)[,] [and] VI.H (Issuance) [and VII (Levy of share of proceeds for adaptation and administrative expenses)] of the annex [and the share of proceeds that is levied to assist developing country Parties that are particularly vulnerable to the adverse effects of climate change to meet the costs of adaptation in addition to those set out in section VI.E (Registration) and VII (Levy of share of proceeds for adaptation and administrative expenses) of the annex];

(e) Provisions for the implementation of the right to appeal and the grievance process as set out in section VI.K of the annex (Other processes associated with Article 6, paragraph 4, activities);

(f) [Provisions that ensure that processes for the mechanism assist Parties to respect, promote and consider their respective obligations on human rights pursuant to section VI.K of the annex (Other processes associated with Article 6, paragraph 4, activities); ]

Option A ssection XI of the annex text and maintaining safeguards and limits in the cover decision as a work programme\}

(g) [Potential provisions that [may][shall] be required on limits to the issuance, transfer, acquisition and/or use of A6.4ERs, including measures to:

(i) [Avoid significant fluctuations in prices, quantities and speculative transfers of A6.4ERs in the international market; ]

(ii) [Address A6.4ERs issued for emission reductions achieved in sectors where there is a high degree of uncertainty in emission estimates;]

(iii) Restrict secondary transfers of A6.4ERs;

(iv) Restrict the quantity of A6.4ERs for transfer;

(v) [Ensure that the use of A6.4ERs towards nationally determined contributions (NDCs) is supplemental to domestic action;]

(vi) [Restrict the use of A6.4ERs towards NDCs by their vintage; ]

(vii) [Restrict the carry-over of A6.4ERs to the subsequent period of NDC implementation; ]

(viii) $[$ Be consistent with provisions that ensure that processes for the mechanism assist Parties to respect, promote and consider their respective obligations on human rights;]]

Option B see section XI of the Annex, where Option B sets out the safeguards and limits in the annex\}

\section{Option C}

(ix) [Use of Article 6 should not lead to an increase in emissions in and between NDC implementation periods; ]

\{end of Option $C$ \}

(h) [Further provisions on the transition of activities from the Kyoto Protocol to Article 6, paragraph 4, that may be required in addition to those set out in section XIII of the annex (Transition from the Kyoto Protocol to Article 6, paragraph 4), including on:

(i) Having the same requirements for joint implementation and clean development mechanism activities as for Article 6, paragraph 4, activities;

(ii) Conditions that may be necessary for the transition of activities, in addition to those set out in section XIII.A of the annex (Transition of activities under the Kyoto Protocol) and in paragraph 7(h)(i) above;

(iii) Necessary steps for the implementation of such transition;]

(i) [Further provisions on the transition of units issued under the Kyoto Protocol that may be required in addition to those set out in section XIII.B (Transition of joint implementation emission reduction units) and section XIII.C (Transition of clean development mechanism certified emission reductions) of the annex;] 
(j) [Potential provisions on the transition of methodologies and accreditation standards from the Kyoto Protocol to Article 6, paragraph 4, that may be required pursuant to section XIII.D (Transition of methodologies) and section XIII.E (Transition of accreditation standards) of the annex; ]

8. [Also requests the SBSTA to develop recommendations on the implementation of the initial provisions of the rules, modalities and procedures for the mechanism in relation to the following, for a draft decision for consideration and adoption by the CMA at its third session:

(a) The Article 6, paragraph 4, activity cycle, as set out in section VI of the annex (Article 6, paragraph 4, activity cycle);

(b) Baseline approaches for Article 6, paragraph 4, activities as set out in section VI.B of the annex (Methodologies);

(c) Demonstration of additionality, as set out in section VI.B of the annex (Methodologies);

(d) The mechanism registry, as set out in section VI.H of the annex (Issuance);

(e) Voluntary cancellation, as set out in section VI.K of the annex (Voluntary cancellation);

(f) The share of proceeds for adaptation, as set out in section VII of the annex (Levy of share of proceeds for adaptation [and adaministrative expenses]);

(g) Delivery of overall mitigation in global emissions, as set out in section VIII of the annex (Delivering overall mitigation in global emissions); ]

9. [Requests the secretariat to collaborate with the forum on the impact of the implementation of response measures (referred to in paragraph 33 of decision 1/CP.21) to consider ways to address any negative social and economic impacts, especially on developing country Parties, resulting from Article 6, paragraph 4, activities by, inter alia regularly sharing relevant information with the forum on the impact of the implementation of response measures in order to support the above activities; ] ssee section XII of the Annex\}

10. [Further requests the secretariat to undertake preparatory technical work, including preparing technical papers and conducting financial and technical feasibility studies as required on the implementation of the rules, modalities and procedures for the mechanism, in particular with regard to the elements listed in paragraph 8 above, for consideration by the SBSTA at its [fifty-second] session;]

11. [[Requests the SBSTA to develop a work programme to assist Parties][Requests the secretariat to assist Parties, in particular developing country Parties, through a work programme] to incorporate sectors and/or gases into their NDC in order for mitigation activities in those sectors and/or gases to become eligible to be Article 6 paragraph 4 activities; ]

12. [Invites Parties to make voluntary contributions for operationalizing the mechanism;]

13. [Takes note of the estimated budgetary implications of the activities to be undertaken by the secretariat referred to in this decision and requests that the actions called for in this decision be undertaken subject to the availability of financial resources; ]

14. [Decides to review these rules, modalities and procedures for the mechanism periodically, and for the first time by no later than the session of the CMA 8 (that will take place at the end of 2025), on the basis of recommendations from the SBSTA and the SBI.] 


\section{Annex}

Rules, modalities and procedures for the mechanism established by Article 6, paragraph 4, of the Paris Agreement

\section{Definitions}

1. For the purpose of these rules, modalities and procedures:

(a) An "Article 6, paragraph 4, activity" is an activity that meets the requirements of Article 6, paragraphs $4-6,{ }^{1}$ these rules, modalities and procedures and any further relevant decisions of the Conference of the Parties serving as the meeting of the Parties to the Paris Agreement (CMA);

(b) An "Article 6, paragraph 4, emission reduction" (hereinafter referred to as an A6.4ER) is issued in respect of mitigation [that delivers real, measurable and long-term benefits related to climate change] achieved pursuant to Article 6, paragraphs 4-6 and these rules, modalities and procedures. It is measured in carbon dioxide equivalent $\left(\mathrm{CO}_{2}\right.$ eq) and equal to $1 \mathrm{t} \mathrm{CO}_{2}$ eq calculated in accordance with the methodologies and common metrics assessed by the Intergovernmental Panel on Climate Change and adopted by the CMA or in other metrics that are adopted by the CMA pursuant to these rules, modalities and procedures;

(c) ["Internationally transferred mitigation outcomes (ITMOs)" are \{definition to be consistent with the guidance on cooperative approaches referred to in Article 6, paragraph 2\}]

(d) ["Overall mitigation in global emissions" is achieved when, through the operation of Article 6, a fixed percentage of emission reductions, duly reported, are not used by any Party or entity to implement or achieve its nationally determined contribution (NDC) or used for any other compliance purposes outside Article 6.] \{text from 8 December SBSTA text, paragraph 1(c)\}

\section{Role of the Conference of the Parties serving as the meeting of the Parties to the Paris Agreement}

2. The CMA has authority over the mechanism established by Article 6, paragraph 4, of the Paris Agreement (hereinafter referred to as the mechanism) and may take further decisions in relation to these rules, modalities and procedures and the mechanism.

3. The CMA shall provide guidance to the Supervisory Body by taking decisions on:

(a) The rules of procedure of the Supervisory Body;

(b) Recommendations made by the Supervisory Body relating to these rules, modalities and procedures;

(c) Matters relating to the operation of the mechanism, as appropriate.

\section{Supervisory Body}

4. The Supervisory Body shall supervise the mechanism pursuant to Article 6, paragraph 4, under the authority and guidance of the CMA, and be fully accountable to the CMA.

\section{A. Rules of procedure}

5. The Supervisory Body shall comprise [12] [22] members from Parties to the Paris Agreement, ensuring broad and equitable geographical representation and [striving to ensure][ensuring] gender-balanced representation, as follows \{some Parties noted the relationship between number of members and need or otherwise for alternates\}: specified.

In the context of this annex, "Article" refers to an Article of the Paris Agreement, unless otherwise 
(a) [Two $][$ Four $]$ members from each of the five United Nations regional groups;

(b) One member from the least developed countries;

(c) One member from small island developing States.

6. The CMA shall elect members [and an alternate for each member] of the Supervisory Body on the basis of nominations by the respective groups or constituencies.

7. Members [and alternate members] shall serve in their individual personal capacity.

8. Members [and alternate members] shall possess relevant scientific, technical, socioeconomic or legal expertise.

9. Members [and alternate members] shall serve for a term of two years.

10. The CMA shall elect half of the first members [and their alternate members] for a term of three years and the other half for a term of two years. At the expiry of the term of such members [and their alternate members] and thereafter, the CMA shall elect half of the members [and their alternate members] for a term of two years. The members [and their alternate members] shall remain in office until their successors are elected.

11. The term of service of a member shall start at the first meeting of the Supervisory Body in the calendar year following his/her election and shall end immediately before the first meeting of the Supervisory Body in the calendar year in which the term ends.

12. [The maximum number of terms of any individual shall be two terms, whether consecutive or not[, and including any period as an alternate member].]

13. If a member [or alternate member] resigns or is otherwise unable to continue as a member [or alternate member], the Supervisory Body may decide, bearing in mind the proximity to the next meeting of the CMA, to appoint a replacement member [or alternate member] from the same constituency to serve the remainder of the term on the basis of a nomination from the Party representing the relevant constitutency, in which case, the appointment shall count as one term.

14. Members [and alternate members] may be suspended or their membership terminated by the CMA if:

(a) They fail to disclose a conflict of interest;

(b) They fail to attend two consecutive meetings without proper justification.

15. Costs for members [and alternate members] will be covered by the share of proceeds for administrative expenses.

16. Members [and alternate members] shall avoid actual, potential and perceived conflicts of interest and shall:

(a) Declare any actual, potential or perceived conflict of interest at the start of a meeting;

(b) Recuse themselves from any discussion in relation to which they have an actual, potential or perceived conflict of interest;

(c) Refrain from behaviour that may be incompatible with the requirements of independence and impartiality.

17. Members [and alternate members] shall ensure confidentiality, in line with best practice for confidentiality.

18. At least three fourths of the members[, including alternate members only when they are acting as members,] shall constitute a quorum for meetings of the Supervisory Body.

19. Members [and alternate members] shall attend meetings [and the alternate members shall act as members if the respective member is not present].

20. Each year, the Supervisory Body shall elect a Chair and a Vice-Chair from among its members. The Chair and the Vice-Chair shall remain in office until their successors are elected.

21. Meetings of the Supervisory Body shall be open to the public, unless closed for reasons of confidentiality.

22. Documents for meetings of the Supervisory Body shall be made publicly available, unless they are confidential.

23. The Supervisory Body shall ensure transparency of decision-making, make publicly available its decision-making framework, and maintain a publicly accessible list of its decisions, including standards, procedures and related documents.

24. Decisions of the Supervisory Body shall be taken by consensus whenever possible. If all efforts at reaching consensus have been exhausted, decisions shall be put to vote and adopted by a majority of three fourths of the members[, including alternate members only when they are acting as members,] present and voting. 
25. The Supervisory Body shall adopt reports on its meetings and make them publicly available.

\section{B. Governance and functions}

26. The Supervisory Body shall, in accordance with further relevant decisions of the CMA:

(a) Establish the requirements and processes necessary to operationalize the mechanism relating to, inter alia:

(i) The accreditation of operational entities;

(ii) The registration of activities as Article 6, paragraph 4, activities and the issuance of A6.4ERs;

(iii) The development [and/or approval] of methodologies (hereinafter referred to as mechanism methodologies) and standardized baselines for Article 6, paragraph 4, activities;

(iv) The registry for the mechanism (hereinafter referred to as the mechanism registry);

Option A $\{$ this option is linked to section V.B\}

(v) [The approval and supervision of national arrangements of host Parties for accreditation of operational entities, development and approval of mechanism methodologies, registration of activities and operation of national registries for the mechanism; ]

Option B

$\{$ no text required $\}$

\{end of Option B\}

(b) Operate the mechanism by, inter alia:

(i) Accrediting operational entities as designated operational entities that meet the relevant requirements for accreditation and managing their performance;

(ii) Taking appropriate measures to promote the regional availability of designated operational entities in all regions;

(iii) [Developing or approving mechanism methodologies; ]

(iv) Registering activities as Article 6, paragraph 4, activities if they meet the relevant requirements for registration;

(v) Approving the issuance of A6.4ERs for registered Article 6, paragraph 4, activities if the relevant requirements for issuance have been met;

(vi) Maintaining the mechanism registry;

(vii) [Supervising the implementation of the share of proceeds levied to assist developing country Parties that are particularly vulnerable to the adverse effects of climate change to meet the costs of adaptation; ]

(viii) [Supervising the implementation of the delivery of an overall mitigation in global emissions; ]

Option A $\{$ this option is linked to section $V . B\}$

(ix) [Supervising and reviewing national arrangements of host Parties for accreditation of operational entities, development and approval of mechanism methodologies, registration of activities and operation of national registries; ]

Option B

$\{$ no text required $\}$

\{end of Option B\}

(c) Support the implementation of the mechanism by, inter alia:

(i) Developing and maintaining a public registry of information related to proposed and registered Article 6, paragraph 4, activities, subject to confidentiality;

(ii) Promoting public awareness of the mechanism; 
(iii) Facilitating the dialogue with host Parties of Article 6, paragraph 4, activities [and other stakeholders in the mechanism];

(iv) [Providing annual information to the CMA on all registered Article 6, paragraph 4 activities hosted by each Party, and all A6.4ERs issued for those activities].

\section{Role of the secretariat}

27. Pursuant to Article 17 and in accordance with further relevant decisions of the CMA, the secretariat shall serve the Supervisory Body [and perform its roles in the operation of the mechanism in accordance with these rules, modalities and procedures].

\section{Participation responsibilities}

28. [Prior to authorizing any Article 6, paragraph 4 activity, each] [Each] Party hosting Article 6, paragraph 4, activities shall, [in addition to its responsibilities in the Article 6, paragraph 4, activity cycle referred to in section VI below (Article 6, paragraph 4, activity cycle),] ensure that:

(a) It is a Party to the Paris Agreement;

(b) It has prepared, has communicated and is maintaining an NDC in accordance with Article 4, paragraphs 2 and 6 and relevant decisions of the CMA;

(c) It has designated a national authority for the mechanism and has communicated that designation to the secretariat;

(d) [It submits national inventory reports referred to in Article 13, paragraph 7(a) in accordance with the modalities, procedures and guidelines as contained in decision 18/CMA.1; \{text based on 8 December SBSTA text, paragraph $30(d)\}]$

(e) [It provides information on all Article 6, paragraph 4, activities hosted by it, and all A6.4ERs that it has transferred internationally or used towards its NDC to [X]; \{some Parties identified a need to say to where the information is provided and how $\}$ ]

(f) It indicates the contribution of the mechanism to its NDC;

(g) [It confirms that it intends to apply corresponding adjustments for A6.4ERs it authorizes for use towards another Party's NDC or any other international mitigation purposes.]

29. [A host Party shall provide to the Supervisory Body its [authorization][approval] of the activity, including: \{text based on paragraphs 49 and 50 below\}

(a) Confirmation that the activity fosters sustainable development in the host Party on the basis of its consideration that it is a national prerogative;

(b) Explanation as to how the activity relates to its NDC;

(c) [In respect of renewals of crediting periods, authorization of the renewal;]

(d) Authorization of the participation of the activity participants in the activity.]

30. [Other participating Parties shall provide to the Supervisory Body, the authorization of the participation of the activity participants in the activity. \{text based on paragraph 50 below\}]

31. [Parties participating in the mechanism should avoid unilateral measures that constitute a means of arbitrary or unjustifiable discrimination or a disguised restriction on international trade in relation to Article 6, paragraph 4, activities in which they participate.]

32. In relation to the least developed countries and small island developing States, pursuant to Article 4, paragraph 6, their special circumstances shall be recognized where these rules, modalities and procedures relate to NDCs, and other aspects of their special circumstances may be recognized in further decisions of the CMA relating to these rules, modalities and procedures.

33. [Parties participating in the mechanism shall ensure their participation is consistent with provisions that assist Parties to respect, promote and consider their respective obligations on human rights.] 
SBSTA 50 - Agenda item 11(b)

34. [The use of the mechanism should not lead to an increase in emissions within or between NDC implementation periods.]

Option A

V. [Rights and responsibilities of host Parties

35. [A Party may choose to host Article 6, paragraph 4, activities in accordance with this section subject to these rules, modalities and procedures and under the supervision of the Supervisory Body.]

\section{A. Specification of participation}

36. [A host Party shall, prior to authorizing activities, specify to the Supervisory Body, in accordance with these rules, modalities and procedures:

(a) [Types of mitigation activities that it intends to authorize pursuant to section VI.C below (Authorization);

(b) [Contribution of activities to mitigation of emissions and to implementation and achievement of its NDC; ]

(c) [Baseline approaches and the types of mechanism methodologies to be applied;]

(d) [Crediting periods to be applied; ]

(e) [How its baseline approaches, mechanism methodologies and crediting periods are compatible with its NDC, and its long-term low greenhouse gas emission development strategy, if available, and how they deliver own benefit;]

(f) [How the participation in the mechanism contributes to sustainable development of the Party.]]

37. [Host Parties shall keep updated the information referred to in paragraph 36 above.]

\section{B. Further optional functions}

38. [A host Party may specify one or more of the following functions it proposes to exercise subject to these rules, modalities and procedures and under the supervision of the Supervisory Body:
(a) [Accreditation of operational entities; ]
(b) [Development and approval of mechanism methodologies; ]
(c) [Specification of baseline approaches; ]
(d) $\quad[$ Specification of crediting periods; $]$
(e) [Registration of mitigation activities; $]$
(f) [Approval of renewal of crediting periods; ]
(g) [Operation of a national registry for the mechanism.]]

Option B

\{no text required $\}$

\section{Article 6, paragraph 4, activity cycle}

\section{A. Activity design}

39. The public or private entities participating in an activity (hereinafter referred to as activity participants) who wish to register the activity as an Article 6, paragraph 4, activity shall design the activity according to the following requirements and any other relevant requirements defined by the CMA or the Supervisory Body: 
(a) [With regard to the types of mitigation, the activity shall achieve emission reductions, [emission removals, ] [emission avoidance] [[the full spectrum of mitigation outcomes,] including mitigation co-benefits of adaptation actions and/or economic diversification plans] (hereinafter collectively referred to as emission reductions) [and shall not include actions referred to in Article 5]][The activity shall achieve mitigation of greenhouse gas (GHG) emissions; ]

(b) With regard to the activity types, the activity shall be a project, programme of activities, or other type approved by the Supervisory Body;

\section{Option A}

(c) The activity shall achieve emission reductions [and emission removals] in the sectors and greenhouse gases [(GHGs)] covered [and not covered] by the NDC of the host Party;

\section{Option B}

(d) [The activity shall achieve emission reductions [and emission removals] in the sectors and greenhouse gases [(GHGs)] covered by the NDC of the host Party;

Option C

\{no text required\}

\{end of Option $C$ \}

(e) With regard to general requirements, the activity shall:

(i) Deliver real, measurable and long-term benefits related to climate change in accordance with decision 1/CP.21, paragraph 37(b);

(ii) [Avoid non-permanence of emission reductions and, in case of reversals, require correction; $]$ text from 8 December SBSTA text, paragraph 31(d)(ii)\} [Incorporate actions to address reversals and displacement of emissions; ]

(iii) Avoid negative environmental [and social] impacts;

(iv) Not lead to an increase in global emissions [in and between NDC implementation periods];

(v) $[\mathrm{Be}$ consistent with provisions that ensure that processes for the mechanism assist Parties to respect, promote and consider their respective obligations on human rights;]

(vi) [Not take into account decreases in economic activity levels and not credit activites that lock-in a level of emissions that is inconsistent with the goal of the Paris Agreement;]

(f) [The activity shall undergo a local and, where appropriate, sub-national stakeholder consultation; ]

(g) The activity shall apply a crediting period for the issuance of A6.4ERs, that is a maximum of [X] years, renewable a maximum of $[\mathrm{Y}]$ times, or a maximum of $[\mathrm{Z}]$ years with no option of renewal, that is appropriate for the activity, and that is subject to approval by the Supervisory Body, [taking into account] [where the baseline is still valid or has been updated to reflect] the technologies or measures, and [relevant circumstances of the activity in the host Party [and changes to policy]][the NDC implementation period of the host Party].

40. The activity shall apply a mechanism methodology approved by the Supervisory Body following its technical assessment, that is developed in accordance with section VI.B below (Methodologies) in order to:

(a) Set a baseline for the calculation of emission reductions to be achieved by the activity;

(b) Demonstrate the additionality of the activity;

(c) Ensure accurate monitoring of emission reductions [and emission removals];

(d) [Take into account any net leakage due to the implementation of the activity.] \{text based on 8 December SBSTA text, paragraph $35(b)\}$

\section{B. Methodologies}

41. Mechanism methodologies may be developed by activity participants, host Parties, stakeholders or the Supervisory Body [for approval by the Supervisory Body]. 
42. Each mechanism methodology shall be transparent, and conservative regarding the choice of approach, assumptions, parametres, data sources, key factors, and take into account uncertainty [and any net leakage due to the implementation of the Article 6, paragraph 4, activity] [and shall [take into account relevant policy][be consistent with the NDC of the host Party] and provide for updates of baselines to reflect changes to policy] [and encourage an increase in ambition over time].

Option A

43. Each [mechanism methodology][activity] shall apply one of the following approaches to setting a baseline for calculating emission reductions, taking into account relevant national, regional or local circumstances, and providing justification for the choice:

(a) A [best available][performance-based] approach, taking into account:

(i) Technologies that represent an economically feasible and environmentally attractive course of action;

(ii) The emissions of activities providing similar outputs and/or services in similar social, economic, environmental and technological circumstances;

(iii) Barriers to investment;

(iv) A contribution to the reduction of the emission levels of the host Party;

(b) Where the approach referred to in paragraph 43(a) above is not considered to be appropriate, an approach based on:

(i) 'Business as usual' emissions;

(ii) Historic emissions.

\section{Option B}

44. [Each [mechanism methodology][activity] shall apply one of the following approaches to setting a baseline for calculating emission reductions, taking into account relevant national, regional or local circumstances, and providing justification for the choice:

(a) A [best available][performance-based] approach, taking into account:

(i) Technologies that represent an economically feasible [and environmentally attractive] course of action;

(ii) The emissions of activities providing similar outputs and/or services in similar social, economic, environmental and technological circumstances;

(iii) Barriers to investment;

(iv) A contribution to the reduction of the emission levels of the host Party;

(v) [The emissions pathway that would be consistent with the achievement of the NDC of the host Party;]

(b) [Where the approach referred to in paragraph 44(a) above is not [considered to be appropriate][applicable], an] [An] approach based on:

(i) ['Business as usual' emissions; ]

(ii) [Historic emissions.]]

\section{Option C}

45. Each mechanism methodology shall apply the following approach to setting a baseline for calculating emission reductions:

(a) The benchmark baseline approach, where a baseline is based on an ambitious benchmark representing a level of GHG emissions for activities within a defined scope and boundary, reflecting best available technology, and taking into account relevant national circumstances or an alternative approach, proposed by the host Party;

(b) An alternative benchmark that comprises a level of GHG emissions for activities within a defined scope and boundary representing a contribution to the reduction of its emission levels and mitigation objectives. 
$\{$ end of Option $C\}$

46. Standardized baselines may be developed by the Supervisory Body at the request of the host Party, or may be developed by the host Party and approved by the Supervisory Body. Standardized baselines shall be established at the highest possible level of aggregation in the relevant sector of the host Party.

47. Each mechanism methodology shall specify the approach to demonstrating the additionality of the activity. The activity is additional where:

(a) Emission reductions achieved by the activity are additional to any that would otherwise occur, [taking into account all relevant national policies, including legislation][and represent mitigation that exceeds any mitigation required by law, regulation, or legally-binding mandate, at the national and subnational levels];

(b) [Emission reductions are [complementary][additional] to the policies and measures [implemented][needed] to achieve the NDC of the host Party.]

48. [The Supervisory Body may waive additionality requirements for any least developed country or small island developing State at the request of that Party.]

\section{Authorization}

49. The host Party shall provide to the Supervisory Body the [authorization][approval] of the activity for requesting registration to be an Article 6, paragraph 4, activity, which shall also include:

(a) The confirmation that the activity fosters sustainable development in the host Party on the basis of its consideration that it is a national prerogative;

(b) [An explanation on how the activity relates to its NDC; ]

(c) [In respect of renewals of crediting periods, authorization of the renewal;

(d) [, if the Party decides to do so, authorization for A6.4ERs issued for the activity to be internationally transferred for use toward NDCs or for purposes other than toward NDCs, and the statement that a corresponding adjustment will be applied to the A6.4ERs by the host Party consistent with the guidance on cooperative approaches referred to in Article 6, paragraph 2.]

50. A participating Party shall provide to the Supervisory Body the authorization of the participation of the activity participants in the activity [and the confirmation that it intends to apply corresponding adjustments for A6.4ERs it uses towards its NDC or that it authorizes for use towards any other international mitigation purposes].

\section{Validation}

51. A designated operational entity shall independently evaluate the activity against the requirements set out in these rules, modalities and procedures, further relevant decisions of the CMA and relevant requirements developed by the Supervisory Body (hereinafter referred to as validation).

\section{E. Registration}

52. If the designated operational entity concludes that the outcome of the validation is positive, it shall submit to the Supervisory Body a request for registration with the validation outcome in accordance with the relevant requirements developed by the Supervisory Body.

53. The activity participants shall pay a share of proceeds to cover the administrative expenses for registering the activity when submitting a request for registration, at the level determined by the CMA.

54. [The activity participants shall pay a share of proceeds to assist developing country Parties that are particularly vulnerable to the adverse effects of climate change to meet the costs of adaptation at the level determined by the CMA.] \{as alternative method for collecting share of proceeds for adaptation through percentage of emission reductions; see section VI.J and section VII below\}

55. If the Supervisory Body decides that the validation and its outcome meet the relevant requirements developed by the Supervisory Body, it shall register the activity as an Article 6, paragraph 4, activity. 
SBSTA 50 - Agenda item 11(b)

\section{F. Monitoring}

56. The activity participants shall monitor [emission reductions achieved] [emissions] by the activity in accordance with the relevant requirements developed by the Supervisory Body.

\section{G. Verification and certification}

57. A designated operational entity shall independently review and determine the implementation of, and the emission reductions achived by, the Article 6, paragraph 4, activity during the monitoring period (hereinafter refered to as verification) against the requirements set out in these rules, modalities and procedures, further relevant decisions of the CMA and relevant requirements developed by the Supervisory Body, and provide written assurance of the verified emission reductions (hereinafter referred to as certification).

\section{H. Issuance}

58. For the issuance of A6.4ERs, the designated operational entity shall submit to the Supervisory Body a request for issuance with the verification outcome and certification in accordance with the relevant requirements developed by the Supervisory Body.

59. The activity participants shall pay a share of proceeds to cover the administrative expenses for issuing A6.4ERs when submitting a request for issuance of A6.4ERs at the level determined by the CMA.

60. If the Supervisory Body decides that the verification, certification and their outcome meet the relevant requirements developed by the Supervisory Body, it shall approve the issuance of A6.4ERs.

61. The mechanism registry administrator shall, in accordance with the relevant requirements developed by the Supervisory Body, issue the A6.4ERs into the mechanism registry.

\section{Option A}

62. [The mechanism registry shall contain at least a pending account, holding account, retirement account, cancellation account, [voluntary] cancellation account for overall mitigation in global emissions] and a share of proceeds account, as well as a holding account for each Party requesting an account.]

Option B

63. [The mechanism registry shall contain at least a pending account, holding account, retirement account, cancellation account[, cancellation account for overall mitigation in global emissions] and a share of proceeds account, as well as a holding account for each Party requesting an account.]

\{end of Option B\}

64. [The mechanism registry shall identify issued A6.4ERs that are authorized by the host Party for international transfer for use toward NDCs or for purposes other than toward NDCs, consistent with the host Party's [authorization][approval] of the registered Article 6, paragraph 4, activities referred to in section VI.C above.]

65. The secretariat shall serve as the mechanism registry administrator and shall maintain and operate the mechanism registry under the authority of the Supervisory Body. \{some Parties identified that the international registry for cooperative approaches referred to in Article 6, paragraph 2 could be combined with the mechanism registry\}

66. [The mechanism registry shall identify issued A6.4ERs that are authorized by the host Party for international transfer for use toward NDCs or for purposes other than toward NDCs, consistent with the host Party's approval of the registered activity referred to in section VI.C above .]

\section{I. [Renewal}

$\{$ text to be developed $\}]$

\section{J. [Forwarding][Transfer] from the mechanism registry}

67. [The mechanism registry administrator shall forward [two][five][X] per cent of the issued A6.4ERs to an account held by the Adaptation Fund for assisting developing country Parties that are particularly vulnerable to the adverse 
effects of climate change to meet the costs of adaptation in accordance with section VII below (Levy of share of proceeds for adaptation).] \{an alternative method for collecting share of proceeds is a monetary amount; see section VI.E above

Option A

68. [The mechanism registry administrator shall, where [voluntary] cancellation applies, in respect of overall mitigation in global emissions, cancel the percentage of the issued A6.4ERs to a cancellation account for delivering overall mitigation in global emissions in accordance with section VIII below (Delivering overall mitigation in global emissions).]

\section{Option B}

69. [The mechanism registry administrator shall, where cancellation applies, in respect of overall mitigation in global emissions, cancel the percentage of the issued A6.4ERs to a cancellation account for delivering overall mitigation in global emissions in accordance with section VIII below (Delivering overall mitigation in global emissions).]

\{end of Option B\}

70. The mechanism registry administrator shall, for the remaining issued A6.4ERs, forward [the specified amount of A6.4ERs in accordance with the instructions of the activity participants] [them to the holding account of the host Party in the mechanism registry][subject to the approval of the host Party if transferred internationally], and [in accordance with] the relevant requirements developed by the Supervisory Body.

\section{K. Voluntary cancellation}

71. Activity participants may request the mechanism registry administrator to cancel [the][a] specified amount of A6.4ERs in accordance with their instructions.

\section{Other processes associated with Article 6, paragraph 4, activities}

72. [Stakeholders, activity participants and participating Parties may appeal decisions of the Supervisory Body or request that a grievance be addressed by the Supervisory Body.]

73. [Stakeholders, activity participants and participating Parties may inform the Supervisory Body of complaints relating to the implementation of paragraph $39(\mathrm{e})(\mathrm{v})$ above.]

\section{Levy of share of proceeds for adaptation [and administrative expenses]}

74. The share of proceeds from an Article 6, paragraph 4, activity that is levied to assist developing country Parties that are particularly vulnerable to the adverse effects of climate change to meet the costs of adaptation shall be delivered to the Adaptation Fund.

\section{Option A}

75. The share of proceeds for adaptation shall be set and levied at [[two][five $][\mathrm{X}]$ per cent at issuance.][[X] per cent at [forwarding][first transfer], increasing by $[\mathrm{Y}]$ per cent at each subsequent transfer.] \{text from 8 December SBSTA text, paragraph 57(c)\}

Option B

76. The share of proceeds for adaptation shall be set and levied at $[\mathrm{X}]$ at [registration][issuance]: \{text for monetary rate needs to be developed?

\{end of Option B\}

77. [The share of proceeds to cover administrative expenses shall be set and levied at [X] at [registration][issuance].] $\{$ text for option of monetary rate and option of the combination of monetary rate and per centage of A6.4ERS needs to be developed\} 


\section{Delivering overall mitigation in global emissions}

\section{Option A}

78. The mechanism shall aim to deliver an overall mitigation in global emissions through any one or a combination of the following:

(a) A voluntary cancellation method by which, following certifcation and verification of emission reductions, the host Party makes a corresponding adjustment consistent with the guidance on cooperative approaches referred to in Article 6, paragraph 2 for the full amount of issued A6.4ERs to be first transferred, and the registry transfers 10 per cent of the total amount of A6.4ERs to a cancellation account for overall mitigation in accordance with section VI.J above ([Forwarding][Transfer] from the mechanism registry); and the cancelled A6.4ERs may not be used for any transfer or purpose, including by any Party towards its NDC or for voluntary cancellation;

(b) Providing a source of mitigation outcomes that enable Parties to select higher ambition in its NDC;

(c) Voluntary cancellation of A6.4ERs by Parties and stakeholders, including non-State actors;

(d) Voluntary measures selected by participating Parties;

(e) Applying conservative baselines, or baselines that are below 'business as usual' levels, to the calculation of emission reductions for Article 6, paragraph 4, activities;

(f) Applying conservative default emission factors to the calculation of emissions from Article 6, paragraph 4 activities.

Option B $\{$ text based on 8 December SBSTA text, paras 58-60\}

79. The mechanism shall aim to deliver an overall mitigation in global emissions in accordance with this section.

\section{Option B1}

80. Overall mitigation in global emissions shall be implemented as follows:

(a) After emission reductions are verified and certified, the host Party [shall] make a corresponding adjustment under the guidance for cooperative approaches referred to in Article 6, paragraph 2 for the full amount of issued A6.4ERs to be first transferred;

(b) At issuance/first transfer of A6.4ERs, the registry shall transfer [X/10/20/30] per cent of total amount of A6.4ERs to the cancellation account for overall mitigation in accordance with section VI above (Article 6 , paragraph 4 , activity cycle);

(c) The cancelled A6.4ERs shall not be used for any transfer or purpose, including by any Party towards its NDC or for voluntary cancellation;

(d) The host Party shall use the remaining A6.4ERs in its account either towards its own NDC or transfer them to another Party's registry or to another Party's account in the mechanism registry.

\section{Option B2}

81. Overall mitigation in global emissions shall be implemented as follows:

(a) After emission reductions have been verified and certified, the host Party [shall] make a corresponding adjustment under the guidance for cooperative approaches referred to in Article 6, paragraph 2 for the full amount of issued A6.4ERs to be first transferred;

(b) The acquiring/using Party shall discount by $[X / 10 / 20 / 30]$ per cent the acquired A6.4ERs at acquisition/use towards its NDC;

(c) The discounted volume of A6.4ERs shall be transferred to the cancellation account for the overall mitigation of global emissions by the acquiring/using Party;

(d) The volume of discounted A6.4ERs shall not be used by any Party towards its NDC or for voluntary cancellation;

(e) The host Party shall use the remaining A6.4ERs in its account either towards its own NDC or transfer them to another Party's registry or another Party's account in the mechanism registry. 
SBSTA 50 - Agenda item 11(b)

Option C text from 8 December SBSTA text, paragraph 61\}

82. Use of the mechanism itself ensures overall mitigation in global emissions

\section{Avoiding the use of emission reductions by more than one Party}

83. Avoiding the use of emission reductions resulting from the mechanism by more than one Party towards its NDC, in accordance with Article 6, paragraph 5, shall be ensured in accordance with this section.

Option A

84. [Pursuant to Article 6, paragraph 5, a Party hosting Article 6, paragraph 4, activities shall make a corresponding adjustment consistent with the guidance for cooperative approaches referred to in Article 6, paragraph 2 for all emission reductions[, if those emission reductions are transferred internationally][from [X date]].]

Option B

85. [Pursuant to Article 6, paragraph 5, a Party hosting Article 6, paragraph 4, activities shall make a corresponding adjustment consistent with the guidance for cooperative approaches referred to in Article 6, paragraph 2, only to emission reductions that are included in the sectors and GHGs covered by its NDC[, if those emission reductions are transferred internationally] [from [X date]].]

Option C

86. [A Party hosting Article 6, paragraph 4, activities shall not be required to make a corresponding adjustment consistent with the guidance for cooperative approaches referred to in Article 6, paragraph 2 for the first transfer of A6.4ERs from the mechanism registry. Pursuant to Article 6, paragraph 5, a Party transferring or acquiring emission reductions after the first transfer from the mechanism shall make a corresponding adjustment consistent with the guidance for cooperative approaches referred to in Article 6, paragraph 2.]

\section{Uses for purposes other than contributions towards nationally determined contributions}

87. [To avoid double use of emission reductions achieved by Article 6, paragraph 4, activities, host Parties shall make an adjustment for emission reductions used for purposes other than contributions towards NDCs, consistent with the guidance for cooperative approaches referred to in Article 6, paragraph 2[, if the A6.4ERs were issued for emission reductions that are achieved in the sectors and GHGs covered by their NDCs].]

\section{Safeguards and limits}

Option A

88. Each participating Party shall apply, [as appropriate][as applicable], any safeguards and limits adopted by the CMA in relation to the mechanism. \{see cover decision paragraph $7(g)$ for work programme on safeguards and limits\}

Option B

89. [Each participating Party shall apply [as appropriate][as applicable], the following safeguards and limits:

(a) [Avoid significant fluctuations in prices, quantities and speculative transfers of A6.4ERs in the international market; ]

(b) [Address A6.4ERs issued for emission reductions achieved in sectors where there is a high degree of uncertainty in emission estimates; ]

(c) Restrict secondary transfers of A6.4ERs;

(d) Restrict the quantity of A6.4ERs for transfer;

(e) [Ensure that the use of A6.4ERs towards NDCs is supplemental to domestic action;

(f) [Restrict the use of A6.4ERs towards NDCs by their vintage;

(g) [Restrict the carry-over of A6.4ERs to the subsequent period of NDC implementation;] 
Option C text from 8 December SBSTA text, paragraph 61\}

82. Use of the mechanism itself ensures overall mitigation in global emissions

\section{Avoiding the use of emission reductions by more than one Party}

83. Avoiding the use of emission reductions resulting from the mechanism by more than one Party towards its NDC, in accordance with Article 6, paragraph 5, shall be ensured in accordance with this section.

\section{Option A}

84. [Pursuant to Article 6, paragraph 5, a Party hosting Article 6, paragraph 4, activities shall make a corresponding adjustment consistent with the guidance for cooperative approaches referred to in Article 6, paragraph 2 for all emission reductions[, if those emission reductions are transferred internationally][from [X date]].]

Option B

85. [Pursuant to Article 6, paragraph 5, a Party hosting Article 6, paragraph 4, activities shall make a corresponding adjustment consistent with the guidance for cooperative approaches referred to in Article 6, paragraph 2, only to emission reductions that are included in the sectors and GHGs covered by its NDC[, if those emission reductions are transferred internationally] [from [X date]].]

\section{Option C}

86. [A Party hosting Article 6, paragraph 4, activities shall not be required to make a corresponding adjustment consistent with the guidance for cooperative approaches referred to in Article 6, paragraph 2 for the first transfer of A6.4ERs from the mechanism registry. Pursuant to Article 6, paragraph 5, a Party transferring or acquiring emission reductions after the first transfer from the mechanism shall make a corresponding adjustment consistent with the guidance for cooperative approaches referred to in Article 6, paragraph 2.]

\section{Uses for purposes other than contributions towards nationally determined contributions}

87. [To avoid double use of emission reductions achieved by Article 6, paragraph 4, activities, host Parties shall make an adjustment for emission reductions used for purposes other than contributions towards NDCs, consistent with the guidance for cooperative approaches referred to in Article 6, paragraph 2[, if the A6.4ERs were issued for emission reductions that are achieved in the sectors and GHGs covered by their NDCs].]

\section{Safeguards and limits}

\section{Option A}

88. Each participating Party shall apply, [as appropriate][as applicable], any safeguards and limits adopted by the CMA in relation to the mechanism. \{see cover decision paragraph $7(g)$ for work programme on safeguards and limits\}

Option B

89. [Each participating Party shall apply [as appropriate][as applicable], the following safeguards and limits:

(a) [Avoid significant fluctuations in prices, quantities and speculative transfers of A6.4ERs in the international market; ]

(b) [Address A6.4ERs issued for emission reductions achieved in sectors where there is a high degree of uncertainty in emission estimates;]

(c) Restrict secondary transfers of A6.4ERs;

(d) Restrict the quantity of A6.4ERs for transfer;

(e) [Ensure that the use of A6.4ERs towards NDCs is supplemental to domestic action; ]

(f) [Restrict the use of A6.4ERs towards NDCs by their vintage; ]

(g) [Restrict the carry-over of A6.4ERs to the subsequent period of NDC implementation; ] 
(h) $\quad[\mathrm{Be}$ consistent with provisions that ensure that processes for the mechanism assist Parties to respect, promote and consider their respective obligations on human rights;]]

Option C

90. [Use of Article 6 should not lead to an increase in emissions in and between NDC implementation periods].

\section{XII. [Addressing negative social and economic impacts under Article 4, paragraph 15 text from 8 December SBSTA text, paragraph 71 \}}

91. The Supervisory Body and the secretariat shall collaborate with the forum on the impact of the implementation of response measures (referred to in paragraph 33 of decision 1/CP.21) to address any negative social and economic impacts, especially on developing country Parties, resulting from Article 6, paragraph 4, activities by, inter alia:

(a) Assessing and identifying negative social and economic impacts of Article 6, paragraph 4, activities, including the cumulative impact of the activities;

(b) Developing, implementing and regularly updating measures to address any negative social and economic impacts of Article 6, paragraph 4, activities, including the cumulative impact of the activities;

(c) Regularly sharing relevant information with the forum on the impact of the implementation of response measures in order to support the above activities.]

\section{XIII. [Transition from the Kyoto Protocol to Article 6, paragraph 4}

\section{A. Transition of activities under the Kyoto Protocol}

Option A

92. [[Projects and programmes of activities registered under joint implementation under Article 6 of the Kyoto Protocol][Project activities and programmes of activities registered under the clean development mechanism under Article 12 of the Kyoto Protocol] may be registered as Article 6, paragraph 4, activities.]

Option B

93. [[Projects and programmes of activities registered under joint implementation under Article 6 of the Kyoto Protocol][Project activities and programmes of activities registered under the clean development mechanism under Article 12 of the Kyoto Protocol] may be registered as Article 6, paragraph 4, activities [that meet the relevant requirements for Article 6, paragraph 4 activities,] subject to the authorization for such registration by the relevant host Party [during a transition period until the mechanism is operational].]

Option C

94. [Project activities and programmes of activities registered under the clean development mechanism under Article 12 of the Kyoto Protocol may be registered as Article 6, paragraph 4, activities [that meet the relevant requirements for Article 6, paragraph 4 activities]. Such registration shall undergo an expedited registration process.]

Option D

95. [No activities registered under joint implementation under Article 6 of the Kyoto Protocol may be registered as Article 6, paragraph 4, activities.]

96. [No activities registered under the clean development mechanism under Article 12 of the Kyoto Protocol may be registered as Article 6, paragraph 4, activities.]

Option E

\{discussion on transition occurs once the design of the mechanism is agreed

\section{B. Transition of joint implementation emission reduction units}

97. [Emission reduction units that are issued for emission reductions that were achieved [prior to][after] 1 January [2020][2021] may be used by a Party towards its NDC; ] 
SBSTA 50 - Agenda item 11(b)

98. [Emission reduction units may not be used by a Party towards its NDC.]

99. [A6.4ERs may be issued for activities registered under joint implementation under Article 6 of the Kyoto Protocol.]

100. [Kyoto Protocol units may not be used by a Party towards its NDC.]

\section{Transition of clean development mechanism certified emission reductions}

101. [Certified emission reductions that are issued for emission reductions that were achieved [prior to][after] 1 January [2020][2021] may be used by a Party towards its NDC.]

102. [Certified emission reductions may not be used by a Party towards its NDC.]

103. [A6.4ERs may be issued for activities registered under the clean development mechanism under Article 12 of the Kyoto Protocol [during the transition period for emission reductions generated after 2020, subject to the compliance of the activities with the requirements referred to in paragraph 93 above].]

104. [Certified emission reductions that have not been cancelled or retired under the Kyoto Protocol may be transferred to the mechanism registry.]

105. [Kyoto Protocol units may not be used by a Party towards its NDC.]

\section{Transition of methodologies}

106. [Baseline and monitoring methodologies under Article 6 of the Kyoto Protocol shall be valid for Article 6 , paragraph 4 activities.]

107. [Baseline and monitoring methodologies under the clean development mechanism under Article 12 of the Kyoto Protocol shall be valid for Article 6, paragraph 4 activities.]

108. [Baseline and monitoring methodologies under the clean development mechanism under Article 12 of the Kyoto Protocol may be relevant for Article 6, paragraph 4 activities.]

\section{E. Transition of accreditation standards}

109. [The accreditation standards and procedures of the clean development mechanism under Article 12 of the Kyoto Protocol should serve as the basis for the standards and procedures for accreditation under the mechanism.]]] 


\title{
APPENDIX 3
}

\author{
DRAFT TEXT
}

on

SBSTA 50 agenda item 11(c)

Matters relating to Article 6 of the Paris Agreement:

Work programme under the framework for non-market approaches referred to in Article 6, paragraph 8, of the Paris Agreement

Version 2 of 26 June 14:30 hrs (edited)

\section{Draft CMA decision on the work programme under the framework for non- market approaches referred to in Article 6, paragraph 8, of the Paris Agreement}

[The Conference of the Parties serving as the meeting of the Parties to the Paris Agreement,

[Recalling the objectives, as referred to in decision 1/CP.21, paragraph 39, of the work programme under the framework for non-market approaches referred to in Article 6, paragraph 8, of the Paris Agreement,]

[Also recalling the Paris Agreement in its entirety, including its preamble,]

[Recognizing that the work programme under the framework for non-market approaches referred to in Article 6, paragraph 8, of the Paris Agreement is to be implemented in the context of the Paris Agreement,]

1. [Adopts the work programme under the framework for non-market approaches referred to in Article 6, paragraph 8, of the Paris Agreement (hereinafter referred to as the work programme) as contained in the annex; ]

2. [Requests the Subsidiary Body for Scientific and Technological Advice to undertake further work to develop and recommend a draft decision on the following elements of the work programme, on the basis of the annex, for consideration and adoption by the Conference of the Parties serving as the meeting of the Parties to the Paris Agreement at its third session (November 2020) as an integral part of the work programme:

(a) [Permanent institutional arrangements for the framework for non-market approaches referred to in Article 6, paragraph 9, of the Paris Agreement (hereinafter referred to as the framework); \{see paragraph 4 of the annex $\}]$ [[Permanent] [Relevant] institutional arrangements for the framework; \{see paragraph 7 of the annex\}] [Rules of procedure of the task force for the framework; $\{$ see paragraph 9 of the annex $\}]$ [[Permanent] institutional arrangements for the framework; \{see paragraph 13 of the annex\}]

(b) Any required reporting arrangements for the framework;]

3. [Also requests the governance of the framework referred to in section III of the annex (governance of the framework) (hereinafter referred to as the A6.8 governance) to identify and recommend focus areas of the work programme activities, which may include, inter alia, the following, for consideration and adoption by the Conference of the Parties serving as the meeting of the Parties to the Paris Agreement at its third session (November 2020):

(a) Joint mitigation and adaptation for the integral and sustainable management of forests;

(b) Social ecological resilience;

(c) [Avoidance of greenhouse gas emissions; ]

(d) [Anthropogenic reduction of emissions by sources and removals [by sinks];

(e) [Ecosystem-based adaptation; $]$

(f) Integrated water management;

(g) Energy-efficiency schemes; 
SBSTA 50 - Agenda item 11(c)

(h) [Adaptation Benefit Mechanism];]

4. [Invites Parties and observer [organizations] to submit via the submission portal, ${ }^{1}$ by 30 March 2020, views and information on:

(a) [Permanent institutional arrangements for the framework, as referred to in paragraph 2(a) above, including their functions, membership and rules of procedure;] [[Permanent] [Relevant] institutional arrangements for the framework, as referred to in paragraph 2(a) above, including their functions, membership and rules of procedure; [Rules of procedure of the task force for the framework, as referred to in paragraph 2(a) above; [ [Permanent] institutional arrangements for the framework, as referred to in paragraph 2(a) above, including their functions, membership and rules of procedure; ]

(b) Any required reporting arrangements for the framework, as referred to in paragraph 2(b) above;

(c) Focus areas of the work programme activities, as referred to in paragraph [15(a)(i)] [15(c)(i)a] of the annex, and existing activities in those focus areas that are considered to be non-market approaches in accordance with the provisions of section II of the annex (non-market approaches under the framework);

(d) Examples of potential activities considered to be non-market approaches in accordance with the provisions of section II of the annex (non-market approaches under the framework) (e.g. [Adaptation Benefit Mechanism and ]Environmental Balance Index);

(e) The tools referred to in paragraph [15(b)] [15(d)(i)] of the annex, including how to operationalize them;]

5. [Requests the secretariat to prepare a technical paper on the matters referred to in paragraph 4(a)(e) above for consideration by the Subsidiary Body for Scientific and Technological Advice at its fiftysecond session (June 2020) [and the A6.8 governance at its first meeting];]

6. [Also requests the secretariat to:

(a) Organize a workshop on the matters referred to in paragraph 4(a)-(b) above and a workshop on the matters referred to in paragraph 4(c)-(e) above in conjunction with the fifty-second session of the Subsidiary Body for Scientific and Technological Advice, ensuring broad participation of relevant experts, subject to the availability of financial resources;

(b) Prepare reports on the workshops for consideration by the Subsidiary Body for Scientific and Technological Advice at its fifty-third session (November 2020) [and the A6.8 governance at its second meeting];]

7. $\quad[$ Decides to:

(a) Review the annual reports of the A6.8 governance and provide guidance to it, where appropriate;

(b) Undertake a review of the work programme at its seventh session (2024) with a view to enhancing the effectiveness of the work programme in implementing the framework, taking into account relevant inputs, including those of the A6.8 governance and the outcomes of the global stocktake, and to adopt a decision on the outcome of the review at the same session;]

8. [Takes note of the estimated budgetary implications of the activities to be undertaken by the secretariat referred to in this decision;]

9. [Requests that the actions called for in this decision be undertaken subject to the availability of financial resources.]

1 https://www4.unfccc.int/sites/submissionsstaging/Pages/Home.aspx 


\section{Annex \\ Work programme under the framework for non-market approaches referred to in Article 6, paragraph 8, of the Paris Agreement}

\section{Principles}

1. In addition to Article $^{1} 6$, paragraphs 8 and 9 , and decision 1/CP.21, paragraph 39, the following principles guide the implementation of the framework for non-market approaches (NMAs) referred to in Article 6, paragraph 9 (hereinafter referred to as the framework) and the work programme under the framework for NMAs referred to in decision 1/CP.21, paragraph 39 (hereinafter referred to as the work programme):

(a) The framework facilitates the use and coordination of NMAs in the implementation of Parties' nationally determined contributions (NDCs), in the context of sustainable development and poverty eradication, and identifies opportunities to enhance linkages and create synergies, inter alia, between mitigation, adaptation, finance, technology development and transfer, and capacity-building;

(b) NMAs under the framework:

(i) Are [voluntary and] not reliant on market-based approaches;

(ii) Do not include transactions or quid pro quo operations;

(iii) Provide a basis for collective action;

(iv) [Enhance a holistic approach for all related sectors; $]$

(v) Avoid duplication with the work of the subsidiary and constituted bodies under the Convention, the Kyoto Protocol and the Paris Agreement.

\section{Non-market approaches under the framework}

2. Each NMA under the framework:

(a) Aims to achieve the aims of NMAs referred to in Article 6, paragraph 8(a)-(c), in an integrated, holistic and balanced manner in the context of Article 6, paragraph 8;

(b) Assists participating Parties in implementing their NDCs;

(c) Involves more than one participating Party;

(d) Does not involve the creation, issuance and transfer of any internationally transferred mitigation outcomes referred to in the guidance on cooperative approaches referred to in Article 6, paragraph 2;

(e) Promotes sustainable development and poverty eradication in participating Parties in accordance with Article 6, paragraph 8;

(f) [Involves a [developed country] Party engaging in a cooperative approach referred to in Article 6, paragraph 2 (hereinafter referred to as a cooperative approach), or an Article 6, paragraph 4, activity referred to in the rules, modalities and procedures for the mechanism established by Article 6, paragraph 4 (hereinafter referred to as an Article 6, paragraph 4, activity), being recognized for the finance, technology transfer and/or capacity-building support it contributes in the course of the cooperative approach or Article 6, paragraph 4, activity, if the mitigation outcomes are not transferred and used only by the host [developing country] Party of the cooperative approach or Article 6, paragraph 4, activity towards its NDC. The recognition of the support provided by the [developed country] Party is proportional

1 "Article" refers to an Article of the Paris Agreement, unless otherwise specified. 
to the mitigation outcomes retained by the host Party in its engagement in the cooperative approach or Article 6, paragraph 4, activity.] \{Some Parties identified a need for refinement for clarity\}

\section{Governance of the framework}

\section{Option A}

3. The framework and the work programme will be implemented by the Subsidiary Body for Scientific and Technological Advice (SBSTA) at its first and second sessional period meeting each year, with its first meeting taking place at SBSTA 52 (June 2020).

4. The SBSTA will consider establishing permanent institutional arrangements for the framework for consideration and adoption by the Conference of the Parties serving as the meeting of the Parties to the Paris Agreement (CMA) at CMA 3 (November 2020).

\section{Option B}

5. An [open-ended working group] [forum for the framework (hereinafter referred to as the NMA forum)] is hereby established to implement the framework and the work programme.

6. The [open-ended working group] [NMA forum] will be convened by the SBSTA Chair and will operate in accordance with the procedures applicable to contact groups and under the guidance of the Chair of the SBSTA. It will meet in conjunction with the first and second sessional period meeting of the SBSTA each year, with its first meeting taking place in conjunction with SBSTA 52 (June 2020).

7. The SBSTA will make recommendations on the establishment of [permanent] [relevant] institutional arrangements for the framework for consideration and adoption at CMA 3 (November 2020).

Option C $\{$ Text from 8 December SBSTA text, Option B, paragraphs 5-8\}

8. A task force for the framework (hereinafter referred to as the task force) is hereby established to maintain and operationalize the broader nature of NMAs, including:

(a) Addressing linkages between mitigation and adaptation, and matching them to the finance, technology development and transfer and capacity-building needs of developing country Parties by building on existing processes and institutional arrangements, such as the Standing Committee on Finance (SCF), the Technology Executive Committee (TEC), the Climate Technology Centre and Network (CTCN), the Paris Committee on Capacity-building (PCCB) and the Local Communities and Indigenous Peoples Platform;

(b) Providing alternative opportunities for the voluntary cooperation of Parties other than cooperative approaches and Article 6, paragraph 4, activities.

9. The task force will be convened by the Chair[s] of the [SBSTA] [SBSTA and the SBI] and will operate in accordance with the rules of procedure of the task force to be set out in decisions of the CMA related to the work programme. The task force will meet twice a year in conjunction with the first and second sessional period meeting of the [SBSTA] [SBSTA and the SBI] each year, with its first meeting taking place in conjunction with [SBSTA 54] [SB 54] (May-June 2021).

10. The task force comprises $[\mathrm{X}]$ members with equal representation of developing country Parties and developed country Parties as follows:

(a) $[\mathrm{X}]$ member from each of the five United Nations regional groups;

(b) $[\mathrm{X}]$ member from developed country Parties;

(c) $[\mathrm{X}]$ member from developing country Parties;

(d) $[\mathrm{X}]$ member from least developed country Parties;

(e) $[\mathrm{X}]$ member from small island developing States;

(f) $[\mathrm{X}]$ members from social organizations nominated by Parties;

(g) $[\mathrm{X}]$ member from the Board of the Green Climate Fund, the TEC and the PCCB. 
11. Two co-chairs of the task force will be appointed, with one being a member from a developing country Party and the other one from a developed country Party.

Option D

12. The framework and the work programme will be implemented by the Subsidiary Body for Scientific and Technological Advice (SBSTA) at its first and second sessional period meeting each year, with its first meeting taking place at SBSTA 52 (June 2020).

13. The SBSTA will consider establishing [permanent] institutional arrangements for the framework for consideration and adoption by the Conference of the Parties serving as the meeting of the Parties to the Paris Agreement (CMA) at CMA 3 (November 2020).

\section{Modalities of the work programme}

14. The modalities of the work programme may include, as appropriate:

(a) Workshops;

(b) Regular meetings with public and private sector participants, including technical experts, businesses, civil society organizations and financial institutions, and the subsequent publication of the outcomes of the meetings;

(c) Submissions from Parties, observer organizations and public and private sector participants;

(d) Technical papers and synthesis reports prepared by the secretariat;

(e) The coordination, where needed, of the governance of the framework referred to in section III above (governance of the framework) (hereinafter referred to as the A6.8 governance) and relevant bodies, institutional arrangements and processes under the Convention, the Kyoto Protocol and the Paris Agreement related to, inter alia, mitigation, adaptation, finance, technology development and transfer, and capacity-building[, including, inter alia, the SCF, the operating entities of the Financial Mechanism, the TEC, the CTCN, the PCCB and the forum on the impact of the implementation of response measures] $\{$ Text based on 8 December SBSTA text, paragraph 12(e)\};

(f) [Consideration of the outputs of the technical examination process on mitigation referred to in decision 1/CP.21, paragraph 109, and that on adaptation referred to in decision 1/CP.21, paragraph 124.] \{Text from 8 December SBSTA text, paragraph 12(f)\}

\section{Work programme activities}

15. The work programme comprises, inter alia, the following activities, which will be implemented from 2020 :

Option A

(a) [Identifying] [Matching needs of and] opportunities for NMAs, in accordance with Article 6, paragraph 8, and the provisions of section II above (non-market approaches under the framework), including on:

(i) Focus areas of the work programme activities for consideration and adoption by the CMA;

(ii) Examples, lessons learned and case studies to promote NMAs;

(iii) Replicating successful NMAs, including in the local, subnational, national and global context;

(iv) Enhancing existing linkages, creating synergies and facilitating the coordination and implementation of NMAs, including in the local, subnational, national and global context;

(v) Leveraging and generating mitigation and adaptation co-benefits that assist in the implementation of NDCs; \{Some Parties identified a need for refinement for clarity\} 
SBSTA 50 - Agenda item 11(c)

(vi) [Approaches to incorporating the mitigation co-benefits from adaptation actions and/or economic diversification as outcomes of cooperative approaches and/or Article 6, paragraph 4, activities that may be used towards NDCs; ] Some Parties identified a need for refinement for clarity\}

(b) Developing and implementing tools, including:

(i) A UNFCCC web-based platform for registering and exchanging information on NMAs and supporting the [identification of] [matching of needs of and] opportunities for participating Parties to develop and implement NMAs, including in relation to finance, technology development and transfer, and capacity-building;

(ii) $\quad[$ Tools for addressing possible negative social and economic impacts of activities under Article 6;]

(iii) Tools for promoting the contribution of NMAs to sustainable development and poverty eradication.

Option B \{Text from 8 December SBSTA text, paragraphs 13(a)-(b), without referring to streams and steps\}

(c) Activities for identifying opportunities to enhance the existing linkages, create synergies, and facilitate coordination and implementation of NMAs, and making recommendations to the CMA:

(i) Identification of NMAs:

a. Identifying focus areas of the work programme activities for consideration and adoption by the CMA at CMA [3/4] [(November 2020/2021)];

b. Identifying existing activities in the focus areas that are considered to be NMAs in accordance with the provisions in section II (non-market approaches under the framework) above;

(ii) Identification of the opportunities:

a. Identifying existing linkages, synergies, coordination and implementation in relation to the NMAs referred to in subparagraph (a)(i)b above;

b. Identifying and evaluating the positive and other experience from the NMAs;

c. Identifying opportunities for enhancing the existing linkages, creating synergies[, and facilitating coordination and implementation of the NMAs], including in the local, subnational, national and global context;

(iii) Recommendations to the CMA of conclusions on the opportunities:

a. Assessing the results of the activities referred to in subparagraphs (a)(i) and (ii) above;

b. Developing and recommending conclusions on how to enhance existing linkages and create synergies [and how to facilitate coordination and implementation of the NMAs] for consideration and adoption by the CMA at CMA [5 (November 2022)];

(d) Activities for implementing the opportunities:

(i) Developing and implementing tools, including:

a. A UNFCCC web-based platform that registers, officially recognizes, and exchanges information on NMAs, [and aims to match the needs] of participating Parties and public and private sector participants for the development and implementation of NMAs, including finance, technology development and transfer and capacity-building, with the support offered by other Parties and other public and private sector participants;

b. Tools for addressing possible negative social and economic impacts of activities under Article 6; 
c. Tools for measuring and monitoring the implementation of NMAs in terms of their contribution to sustainable development and poverty eradication;

(ii) Identifying and sharing relevant information, best practices, lessons learned and case studies for the development and implementation of NMAs, including on:

a. Opportunities for replicating successful NMAs, including in the local, sub-national, national and global context;

b. [Enabling environments and successful policy frameworks and regulatory approaches for developing and implementing NMAs; ]

c. [Barriers to and incentives for: enhancing the engagement in NMAs of and addressing the needs of the private sector, and vulnerable and impacted sectors and communities; and achieving a just transition of the workforce; ]

d. Opportunities for leveraging and generating mitigation and adaptation co-benefits;

e. Approaches to incorporating the mitigation co-benefits from adaptation actions and/or economic diversification as outcomes of cooperative approaches and/or Article 6, paragraph 4, activities, that may be used towards NDCs.

\section{Reporting}

16. The progress and outcomes of the work programme will be reported on the basis of information resulting from, inter alia, the modalities of the work programme and the work programme activities referred to in section IV (modalities of the work programme) and V (work programme activities) above, respectively, by the A6.8 governance at each session of the CMA, including, as relevant:

(a) Recommendations for conclusions on opportunities to enhance NMAs, including on:

(i) The results of the activities referred to in paragraph [15(a) and (b)] [15(c) and (d)] above;

(ii) How to enhance existing linkages and create synergies and how to facilitate coordination and implementation of NMAs for consideration and adoption by the CMA;

(b) Recommendations on how to enhance support for NMAs with respect to possible activities of relevant bodies, institutional arrangements and processes under the Convention, the Kyoto Protocol and the Paris Agreement related to, inter alia, mitigation, adaptation, finance, technology development and transfer, and capacity-building;

(c) Recommendations on enhancing the effectiveness of the work programme in implementing the framework.

17. Where the SBSTA concludes that there is a need for new reporting arrangements for the framework, it will make recommendations on such reporting for consideration and adoption at CMA 3 (November 2020).] 



\section{Negotiations on Article 6 of the Paris Agreement Road to Madrid}

The climate meeting in Katowice (COP 24) in 2018 resulted in the adoption of the Paris Agreement Rulebook, which is the operationalization of the Paris Agreement. However, an important part of the Rulebook, Article 6, was pushed to COP 25 in Madrid 2019. Article 6 provides the foundations for post2020 carbon markets as well as nonmarket approaches. This paper recalls the outcome from Katowice and elaborates key issues and key positions among Parties taking stock of the negotiation meeting held in Bonn, Germany, in May 2019. The paper analyzes issues, highlights the most relevant discussions, and outlines possible outcomes of COP 25 in Madrid in light of the need to establish a credible framework for the future carbon market.

\section{About the Asian Development Bank}

ADB is committed to achieving a prosperous, inclusive, resilient, and sustainable Asia and the Pacific, while sustaining its efforts to eradicate extreme poverty. Established in 1966, it is owned by 68 members -49 from the region. Its main instruments for helping its developing member countries are policy dialogue, loans, equity investments, guarantees, grants, and technical assistance. 